\title{
Columnar modelling of nucleation burst evolution in the convective boundary layer - first results from a feasibility study Part IV: A compilation of previous observations for valuation of simulation results from a columnar modelling study
}

\author{
O. Hellmuth \\ Leibniz Institute for Tropospheric Research, Modelling Department, Permoserstrasse 15, 04318 Leipzig, Germany
}

Received: 1 August 2005 - Published in Atmos. Chem. Phys. Discuss.: 10 November 2005

Revised: 14 February 2006 - Accepted: 29 May 2006 - Published: 21 September 2006

\begin{abstract}
In the preceding Papers I, II and III a revised columnar high-order modelling approach to model gas-aerosol-turbulence interactions in the convective boundary layer $(\mathrm{CBL})$ was proposed, and simulation results of two synthetic nucleation scenarios (binary vs. ternary) on new particle formation (NPF) in the anthropogenically influenced CBL were presented and discussed. The purpose of the present finishing Paper IV is twofold: Firstly, an attempt is made to compile previous observational findings on NPF bursts in the CBL, obtained from a number of field experiments. Secondly, the scenario simulations discussed in Paper III will be evaluated with respect to the role of CBL turbulence in NPF burst evolution. It was demonstrated, that completely different nucleation mechanisms can lead to the occurrence of NPF bursts in the surface layer, but the corresponding evolution patterns strongly differ with respect to the origin, amplitude and phase of the NPF burst as well as with respect to the time-height evolution of turbulent vertical fluxes and double correlation terms of physicochemical and aerosoldynamical variables. The large differences between the binary and ternary case scenario indicate, that ammonia $\left(\mathrm{NH}_{3}\right)$ can not be considered as a time-independent tuning parameter in nucleation modelling. Its contribution to the evolution of the NPF burst pattern is much more complicated and reflects the influence of CBL turbulence as well as the strong non-linearity of the ternary nucleation rate. The impact of water $\left(\mathrm{H}_{2} \mathrm{O}\right)$ vapour on the nucleation rate is quite varying depending on the considered nucleation mechanism. According to the classical theory of binary nucleation involving $\mathrm{H}_{2} \mathrm{O}$ and sulphuric acid $\left(\mathrm{H}_{2} \mathrm{SO}_{4}\right)$, $\mathrm{H}_{2} \mathrm{O}$ vapour favours NPF, according to the classical theory
\end{abstract}

Correspondence to: O. Hellmuth

(olaf@tropos.de) of ternary nuncleation involving $\mathrm{H}_{2} \mathrm{O}, \mathrm{H}_{2} \mathrm{SO}_{4}$ and $\mathrm{NH}_{3}$ and according to organic nucleation via chemical reactions involving stabilised Criegee intermediates (SCIs), $\mathrm{H}_{2} \mathrm{O}$ vapour disfavours nucleation, and according to the parameterisation of the collision-controlled binary nucleation rate proposed by Weber et al. (1996), $\mathrm{H}_{2} \mathrm{O}$ vapour does not explicitly affect the particle formation. Since the $\mathrm{H}_{2} \mathrm{SO}_{4}$ concentration is overpredicted in the simulations presented in Paper III, the nucleation rates are too high compared to previous estimations. Therefore, the results are not directly comparable to measurements. Especially NPF events, where organics are suspected to play a key role, such as those observed at the boreal forest station in Hyytiälä (Southern Finland) or at Hohenpeissenberg (mountain site in Southern Germany), can not be explained by employing simple sulphur/ammonia chemistry. However, some valuable hints regarding the role of CBL turbulence in NPF can be obtained. In the literature a number of observations on the link between turbulence and NPF can be found, whose burst patterns support a strong contribution of CBL turbulence to the NPF burst evolution simulated here. Observations, that do not correspond to the scenarios are discussed with respect to possible reasons for the differences between model and observation. The model simulations support some state-of-the-art hypotheses on the contribution of CBL turbulence to NPF. Considering the application of box models, the present study shows, that CBL turbulence, not explicitly considered in such models, can strongly affect the spatio-temporal NPF burst evolution. The columnar high-order model presented here is a helpful tool to elucidate gas-aerosol-turbulence interactions, especially the genesis of NPF bursts in the CBL. An advanced description of the cluster formation and condensation growth is required as well as a comprehensive verification/validation study using 
observed high-order moments. Further scenario simulations remain to be performed.

\section{Introduction}

Based on a comprehensive compilation of observational findings on atmospheric NPF in the planetary boundary layer (PBL), an attempt is made to evaluate the binary and ternary nucleation scenario presented in Paper II and III from a "macroscopic" point of view, i.e., at scales, where gasaerosol-turbulence interactions in the boundary layer become important. Here, "microscopic" processes of nucleation, i.e., processes occurring at the molecular scale, are briefly discussed in the context of the modern concept of formation and activation of thermodynamically stable clusters (TSCs) and of Nano-Köhler theory proposed by Kulmala et al. (2000), Kulmala (2003) and Kulmala et al. (2004a). The aim of the present paper is to compare the simulation results on NPF in the CBL, presented in Paper II and III, with the typically observed daytime evolution of the surface-based total particle number concentration, the turbulent heat flux, the wind variance and the temperature variance as well as the particle flux.

\section{General behaviour of NPF bursts in the planetary boundary layer}

One of the first comprehensive observational studies on NPF in the polluted CBL (over a 1.5-year period, 26 March 1996 to 15 August 1997) was published by Birmili and Wiedensohler (2000) ${ }^{1}$. Significant NPF events, characterised by a number concentration of ultrafine condensation nuclei (UCNs) $>10^{4} \mathrm{~cm}^{-3}$ in the size range $3-11 \mathrm{~nm}$, were observed on $20 \%$ of all days. On $80 \%$ of the significant event days the sulphur dioxide $\left(\mathrm{SO}_{2}\right)$ concentration was increased by an average factor of 7 . From the slightly enhanced concentration of the pre-existing particle surface area on event days it was concluded, that the competition between condensation onto the pre-existing particle surface area and the NPF process must have been weak (Birmili and Wiedensohler, 2000, Fig. 2). Highest statistical correlation was found between NPF events and solar radiation (Birmili and Wiedensohler, 2000, Table 2). The typical shape of a NPF event, e.g., the one observed on 7 June 1997 using two Condensation Particle Counters (CPCs), resembles a "banana"-form ${ }^{2}$ (Birmili and Wiedensohler, 2000, Fig. 1). The coincidence of high values of the UCN number concentration, $\mathrm{SO}_{2}$ concentration and solar irradiance is a strong evidence for the key contribution of photooxidation in NPF. Furthermore, Birmili

\footnotetext{
${ }^{1}$ Research station Melpitz: $51.526^{\circ} \mathrm{N}, 12.928^{\circ} \mathrm{E}, 87 \mathrm{~m}$ above sea level (a.s.1.), $42 \mathrm{~km}$ north-east of Leipzig, Eastern Germany.

${ }^{2}$ In the literature, this evolution pattern was later on sometimes synonymously abbreviated as "banana plots".
}

and Wiedensohler (2000, p. 3328) concluded, that "although solar radiation is the trigger for photochemical reaction, the meteorological data also indicate a stronger mixing of the boundary layer on event days, which indicates meteorological control of the new particle formation process."

Within the Hohenpeissenberg Aerosol Formation Experiment (HAFEX) Birmili et al. (2003) evaluated a number of time series of NPF events over a 2.5-year period (April 1998 to August 2000) ${ }^{3}$. NPF events were detected on $18 \%$ of all days, typically during midday hours under sunny and dry conditions, whereas the number of newly formed particles was found to be significantly correlated with solar irradiance and ambient levels of $\mathrm{H}_{2} \mathrm{SO}_{4}$ vapour. NPF events were observed to be anti-correlated with the pre-existing particle surface area, especially in the cold season in association with advection of dry and clean air from the Alps. The UCN number concentrations were generally low at night-time. During darkness, not a single NPF event was observed. This supports a key role of photooxidation in NPF. On NPF event days, high UCN number concentrations occurred predominantly around noon. UCN number concentrations typically peaked around $2000-30000 \mathrm{~cm}^{-3}$, and hydroxyl radical $(\mathrm{OH})$ and $\mathrm{H}_{2} \mathrm{SO}_{4}$ vapour showed a pronounced daytime variation of the concentration, also peaking around noon with maximum concentrations in the range $(1-2) \times 10^{7} \mathrm{~cm}^{-3}$.

Strong NPF burst behaviour also appeared in a number of typical particle concentration time series observed at the boreal forest measurement station Hyytiälä4: 13 March 1996 (Kulmala et al., 2004d, Fig. 2), 19 September 1996 (Clement et al., 2001, Fig. 1), 14 April 1999 (Kulmala et al., 2001a, Fig. 1), 19 Mai 1999 (Boy and Kulmala, 2002a, Fig. 1). The time of burst onset and the burst amplitude, appearing in that time series, coincide well with the general time evolution of the binary NPF scenario simulated in Paper III. According to Boy and Kulmala (2002a, Table 1), the majority of observed NPF events sets in ante meridiem or around noon. The NPF events were found to be strongly correlated with a photochemically produced condensable vapour. The authors empirically derived a nucleation parameter by dividing UV-A solar radiation by the water vapour concentration and temperature. On average, NPF was found to occur, when the nucleation parameter exceeds a certain threshold. The observed

\footnotetext{
3 Meteorological Observatory Hohenpeissenberg: $47^{\circ} 48^{\prime} \mathrm{N}$, $11^{\circ} 07^{\prime} \mathrm{E}$, rural continental mountain site in Southern Germany, approximately $50 \mathrm{~km}$ north of the Alps, $980 \mathrm{~m}$ a.s.1., and approximately $300 \mathrm{~m}$ above the surrounding countryside.

${ }^{4}$ Hyytiälä Forestry Field Station of the University of Helsinki: $61^{\circ} 51^{\prime} \mathrm{N}, 24^{\circ} 17^{\prime} \mathrm{E}, 180 \mathrm{~m}$ a.s.l., SMEAR II (Station for Measuring Forest Ecosystem - Atmosphere Relations), forest region in central Southern Finland dominated by extended areas of Scots Pine (Pinus sylvestris). The conditions at the site are typical for a background location. However, the station buildings ( $0.5 \mathrm{~km}$ away) and the city of Tampere ( $60 \mathrm{~km}$ away) - both located in a west-southwest direction from the instruments, $215-265^{\circ}$ ) occasionally polluted measurements (Boy et al., 2005, p. 864).
} 
$\mathrm{H}_{2} \mathrm{SO}_{4}$ concentrations at Hyytiälä were lower than those simulated in the present study. Owing to the observed low acidity the authors argued, that the theory of homogeneous binary nucleation can not explain the observed NPF burst behaviour.

The semi-empirical modelling approach of Clement et al. (2001) supports the hypothesis, that NPF bursts in Hyytiälä are initiated by a vapour, which was produced by solar radiation on a precursor. The vapour is removed by condensation on pre-existing aerosol particles, whereas the vapour concentration depends on the ratio of radiation intensity to the removal rate. Clement et al. (2001) found, that NPF bursts occur, when the vapour concentration exceeds a certain value (Clement et al., 2001, p. 222, items (A)-(C)). The authors let the question concerning the nature of that vapour open. Anyway, the time evolution of their predicted NPF pattern is also obtained using the present columnar approach.

In their NPF characterisation study, Aalto et al. (2001) evaluated observed particle concentrations and size distributions inside and above a boreal forest during three BIOFOR campaigns (Biogenic Aerosol Formation Over the Boreal Forest, 14 April-22 May 1998, 27 July-21 August 1998, 20 March-24 April 1999) in Hyytiälä. On average over the whole campaign, NPF events were observed during sunny days, whereas clouds were observed to efficiently suppress particle formation due to reduced photochemical activity. During all events, particle surface area and volume were lower than their averages. The authors derived a threshold of global radiation below which and a threshold of particle surface area concentration above which NPF was not detected. On NPF event days, enhanced concentrations of $\mathrm{SO}_{2}$ and $\mathrm{NH}_{3}$ were observed, whereas a key role of $\mathrm{NH}_{3}$ in nucleation was not claimed. Most often, NPF events started between 08:00 a.m. and 11:00 a.m. The time evolution of the observed NPF bursts in Hyytiälä was found to be similar to the binary UCN evolution depicted in Fig. 11a of Paper III, but the observed NPF events occurred at a lower acidity level.

\section{Turbulence-related NPF}

\subsection{Hypothesis}

Kulmala et al. (2001a, Fig. 1) explained their NPF observations by Nilsson's NPF mixing hypothesis, according to which NPF typically follows the breakup of a nocturnal boundary layer, leading to subsequent vigorous mixing with air from the residual boundary layer (Nilsson et al., 2001a). In their comprehensive NPF-CBL evolution study Nilsson et al. (2001a, Sect. 4.1, item (1)) hypothesised, that "on days, when dilution of the pre-existing aerosol number and condensation sink was observed before nucleation, this may itself be enough to trigger nucleation by decreasing the sink of precursor gases at the same time, that the precursor production may be increasing due to increasing photochemical activity. Such a scenario would form favourable con- ditions for nucleation". The present binary case simulation shows, that under certain circumstances NPF can occur in the upper part of the growing CBL, followed by downward transport of newly formed particles. In such cases entrainment of free-tropospheric air does not contribute to NPF, but the onset of turbulence is a prerequisite to sample UCNs in the surface layer. The binary scenario simulated here is a direct corroboration of Nilsson's first hypothesis.

The CBL turbulence scenario simulated in Paper II agrees well with the conditions observed on NPF event days during the BIOFOR campaign at the SMEAR II measurement station. For a detailed description of the typical diurnal evolution of the boundary layer on NPF event days the reader is referred to Nilsson et al. (2001a, Subsection 3.1) and Buzorius et al. (2003, p. 2-3, item 14).

Nilsson et al. (2001a, pp. 449-452) reported: "It appears, that on all nucleation days during BIOFOR, the nucleation was observed $10 \mathrm{~min}$ to $2 \mathrm{~h}$ after the onset of the convection, strong turbulence and entrainment, typically in the late morning, but sometimes earlier and sometimes later.[...] The appearance of $3 \mathrm{~nm}$ particles was always observed after the onset of strong turbulence." On p. 450 the authors denoted: "The sunlight will cause both more turbulence along with more $\mathrm{OH}$ production, consequently, it is very difficult to determine which has a dominating effect, or if both processes were of similar importance for the onset of nucleation.[...] It appears, that it is more likely that the increase in turbulence in the morning controls the onset of nucleation than that the increase in photochemistry occupies this key role." On p. 452 they wrote: "The table indicates, that by the time nucleation started, there was always a mixed layer. This implies, that mixing of the near-surface air with the air from stable layer above or the residual layer had occurred.".

The present study shows, that the sampling of enhanced "burst"-like UCN number concentrations near the ground is a result of interactions between CBL turbulence and photochemistry. In Paper III it was demonstrated, how this interactions go by. Hence, the suggestions of Nilsson et al. (2001a) regarding these processes are confirmed. In general, the simulations correspond very well to the meteorological conditions, especially the CBL turbulence observed during NPF bursts in the BIOFOR campaign and to the explanations given by Nilsson et al. (2001a).

\subsection{Connection between the onset of NPF and the onset of turbulence}

Buzorius et al. (2003) observed a coincidence between NPF, elevated variances of temperature and vertical wind speed as well as an enhanced turbulent heat flux. During NPF event days SODAR-based vertical wind variances at $200-300 \mathrm{~m}$ altitude showed slightly higher values compared to values below $100 \mathrm{~m}$ (Buzorius et al., 2003, Figs. 1-2). To quantify the average influence of turbulence on NPF, the authors empirically derived functional dependencies for the so-called "par- 
ticle formation probability", which increases with increasing values of the heat flux, the vertical wind variance and the temperature standard deviation (Buzorius et al., 2003, Figs. 3-4). The maximum daily values of these three turbulence parameters on NPF event days were observed to occur after NPF had happened. At the onset of NPF, these parameters were not different yet from those on non-event days. On NPF event days, condensation sink was significantly lower compared to other days (Buzorius et al., 2003, item 39). With respect to the present binary scenario simulation, these observations are directly confirmed by the simulated time at which the corresponding turbulence and NPF parameters exceed their maximum in the surface layer (see Figs. 8a, b of Paper II for turbulent heat flux and vertical wind variance; Fig. 11a in Paper III for the binary UCN burst).

Based on the fact, that NPF coincides with a comparatively low pre-existing particle surface area and condensation sink, NPF was observed to be favoured by the dilution of the condensation sink during the growth of the CBL. The dilution is caused by re-coupling between the surface layer and the nocturnal residual layer with lower aerosol concentration $(\mathrm{Bu}-$ zorius et al., 2003, p. 2-6, item 25). However, it was not obvious, that intense turbulent mixing (fully developed turbulence) is triggering the nucleation. Buzorius et al. (2003) argued, that mixing in terms of moving air parcels across the inversion may enhance the nucleation rate by turbulent fluctuations as suggested by Nilsson and Kulmala (1998). According to Buzorius et al. (2003) it is more likely, that NPF is triggered by mixing of surface layer air, enriched with condensable vapours and pre-existing aerosol particles, with clean residual layer air. Notwithstanding, the authors proposed the possibility, that NPF occurs above the surface layer and after clean nocturnal residual layer air starts mixing with surface layer air, this way reducing the pre-existing particle surface. This mixing process is followed by transport of new particles to the surface. In the present study, mixinginduced dilution of pre-existing particle concentration does not efficiently contribute to NPF, because the pre-existing particle concentration was quite low in the considered scenarios. However, the way, that ex situ formed new particles can be sampled at the surface as a consequence of CBL turbulence, has been clearly demonstrated here.

Stratmann et al. (2003) investigated NPF events in the CBL during the SATURN experiment ("Strahlung, vertikaler Austausch, TURbulenz und Partikel-Neubildung", radiation, vertical exchange, turbulence and new particle formation, 27 May to 14 June 2002) at three measurements sites in the Leipzig region, Eastern Germany, classified as rural and urban influenced with varying distances to the city of Leipzig $^{5}$. As far as known, the authors were the first, who

\footnotetext{
${ }^{5}$ Melpitz: $51.526^{\circ} \mathrm{N}, 12.928^{\circ} \mathrm{E}, 87 \mathrm{~m}$ a.s.1., $42 \mathrm{~km}$ north-east of Leipzig; Collm: $51.3077^{\circ} \mathrm{N}, 13.0026^{\circ} \mathrm{E}, 230 \mathrm{~m}$ a.s.1., $40 \mathrm{~km}$ southeast of Leipzig; Panitzsch: $51.361^{\circ} \mathrm{N}, 12.544^{\circ} \mathrm{E}, 139$ a.s.1., $10 \mathrm{~km}$ east of Leipzig
}

measured the vertical distribution of particle number concentrations and turbulence using a tethered-balloonborne payload (ACTOS, Airship-borne Cloud Turbulence Observation System), accompanied by coinciding SODAR and LIDAR observations. The 3 June 2002 was a typical NPF event day with textbook-like CBL conditions, as can be seen from SODAR, LIDAR and radiosounding data (Stratmann et al., 2003, Figs. 7-11). This NPF event day featured an increase in global radiation (a radiation maximum near $1000 \mathrm{Wm}^{-2}$ ) and temperature as well as decreasing relative humidity in the course of the day, i.e., a daytime evolution, that is typical for clear sky conditions. The $\mathrm{SO}_{2}$ concentration peaked at 08:00 UTC, $0.5-1 \mathrm{~h}$ after the breakup of the nocturnal inversion layer and at 12:00 UTC. The $\mathrm{NH}_{3}$ concentration increased fast in the early morning, afterwards decreasing during daytime. The number concentrations of particles in the diameter ranges $D_{p}=3-10 \mathrm{~nm}$ and 3-800 nm significantly increased at 07:30 UTC, both number concentrations featuring a second maximum between 10:30 and 12:00 UTC. The evolution of both followed the evolution of $\mathrm{SO}_{2}$ (Stratmann et al., 2003, Fig. 10). This behaviour strongly indicates, that NPF was controlled by photooxidation of $\mathrm{SO}_{2}$ involving $\mathrm{OH}$. The key feature of the observed NPF event was the pronounced increase of the UCN number concentration (diameter range $D_{p}=3-20 \mathrm{~nm}$ ) approximately at 07:30 UTC, taking place half an hour after the breakup of the nocturnal inversion at around 07:00 UTC and coinciding with the first $\mathrm{SO}_{2}$ peak (Stratmann et al., 2003, Fig. 7, SODAR; Fig. 10d). For details of the evolution of the number size distribution the reader is referred to Stratmann et al. (2003, p. 1454). The significant changes of the size distribution took place in the course of the breakup of the nocturnal inversion. The ground-based observations at Melpitz revealed, that NPF occurred about $0.5-1 \mathrm{~h}$ after the breakup of the nocturnal inversion until the mixing layer had reached the CBL top at approximately $1000 \mathrm{~m}$ after a few hours (Stratmann et al., 2003, Fig. 9, LIDAR). To elucidate the role of CBL turbulence, a number of ACTOS profiles were evaluated. The descent from $830 \mathrm{~m}$ to the ground level (06:31-06:53 UTC) indicated a temperature inversion between 150 and $200 \mathrm{~m}$, and the $\mathrm{H}_{2} \mathrm{O}$ vapour density revealed strong fluctuations inside the mixed layer (Stratmann et al., 2003, Fig. 14). The vertical profiles of the number concentrations $N_{I}\left(10<D_{p}<1500 \mathrm{~nm}\right), N_{I I}\left(5<D_{p}<1500 \mathrm{~nm}\right)$ and $\Delta N\left(5<D_{p}<10 \mathrm{~nm}\right)$ clearly depicted a three-layer structure: mixed layer, inversion layer, residual layer. Here, we focus on the UCN profile, represented by $\Delta N$. In a narrow region above the inversion (between 250 and $300 \mathrm{~m}$ ), no small particles could be observed. Above the inversion, $\Delta N$ increased up to values of $800 \mathrm{~cm}^{-3}$ between 400 and $600 \mathrm{~m}$. This behaviour nearly coincided with the $\mathrm{SO}_{2}$ profile, which showed a pronounced minimum at approximately $220 \mathrm{~m}$. The $\Delta N$-profile showed, that between 06:26 and 06:53 UTC NPF occurred in the residual layer. The ascent from the ground level to $610 \mathrm{~m}$ (08:43-08:48 UTC) 
showed the disappearance of the inversion and the appearance of a near-adiabatic stratification. From the ground up to $550 \mathrm{~m}, \Delta N$ varied between 1000 and $5000 \mathrm{~cm}^{-3}$, above $550 \mathrm{~m} \Delta N$ decreased rapidly to zero. At this time, the $\mathrm{SO}_{2}$ profile was nearly independent of height. Afterwards, the balloon remained at $600 \mathrm{~m}$. The time series of $\Delta N$, observed at this height, showed variations of several orders of magnitude with maximum values of $4000-5000 \mathrm{~cm}^{-3}$. This behaviour was related to updrafts, temporarily penetrating into the residual layer. The tethered-balloonborne payload was sometimes inside of such an updraft with highly increased turbulence and a significant number of UCNs, and sometimes inside the residual layer, where turbulence was much weaker and $\Delta N$ was close to zero (no detection of UCNs). Hence, during the total sampling interval between 08:43 and 09:05 UTC, NPF took place in the entire CBL, while inside the residual layer no UCNs were observed.

Stratmann et al. (2003, p. 1456) summarised their observational findings as follows:

1. NPF occurred inside the residual layer before the breakup of the nocturnal inversion.

2. UCNs, formed in the residual layer, grew up and were mixed down during the breakup process of the nocturnal inversion.

3. No NPF was observed in the residual layer after the breakup of the nocturnal inversion.

4. During and after the breakup of the nocturnal inversion NPF was observed in the mixed layer.

What actually happened on 3 June 2002 was the occurrence of two different NPF events, one inside the residual layer before and the second in the mixed layer during and after the breakup of the nocturnal inversion. With respect to the second event the authors interpreted their results as a direct corroboration of the hypothesis of Nilsson et al. (2001b) on the correlation between the onset of NPF and the onset of turbulence. The present binary case simulation supports that interpretation, i.e., at least the second NPF event on 3 June 2002 corresponds to the gas-aerosol-turbulence interaction simulated in the binary scenario of Paper III. Stratmann et al. (2003) suggested, that the NPF event observed in the residual layer points toward hypothesis 3 of Nilsson et al. (2001b), according to which particles newly formed in the residual layer may grow up into a detectable size range inside the residual layer. As shown in the ternary case scenario, the ternary nucleation might be a way to initiate NPF in the residual layer (see Figs. 4b, d and Fig. 11a of Paper III). However, a scenario of NPF in the residual layer remains to be simulated within a framework like the present conceptual study.

The most direct observational evidence, supporting NPF at the CBL top followed by top-down diffusion of UCNs, was provided by Siebert et al. (2004). The authors evaluated ACTOS profile measurements, obtained during the NPF event on 30 May 2002 of the SATURN experiment. This event day was the only one with observation of enhanced concentrations of UCNs near the inversion layer, accompanied by high fluctuations of the potential temperature and water vapour density (Siebert et al., 2004, Figs. 1-2). The observed UCNs at the inversion were demonstrated to be newly formed and not transported upward from the ground against their mean gradient. Simultaneously with the significantly enhanced UCN number concentration near the inversion, an increase of the UCN number concentration at the ground was observed (Siebert et al., 2004, Fig. 3, peak of $\sim 10 \times 10^{2} \mathrm{~cm}^{-3}$ at 07:30 UTC). To explain ground-based UCN time series by top-down diffusion, Siebert et al. (2004, Figs. 3-4) applied a diffusion model based on "K-theory" to the observed UCN profile. The authors demonstrated, that "no further sources for ultrafine particles in addition to the NPF event at the inversion are needed to explain the increase of ultrafine particle number concentration at ground level" (Siebert et al., 2004 , p. 4 of 4). This observation directly corroborates the hypothesis of Nilsson et al. (2001b), according to which new particles may form due to effective mixing near the inversion layer, followed by downward transport of UCNs leading to an enhanced particle concentration at the ground level. Consequently, the NPF event on 30 May 2002 corresponds to the NPF burst evolution, simulated in the binary case scenario of Paper III.

\subsection{Observation of vertical fluxes during NPF events}

During the BIOFOR NPF event on 2 April 1999, Aalto et al. (2001, pp. 353-354, Fig. 8) observed, that "[...] particle concentration did not increase equally at different heights. Inside the forest, the concentration was approximately half of the concentration above the forest during the strongest events". For the BIOFOR NPF event on 12 April 1999, Nilsson et al. (2001a, Fig. 9) depicted the turbulent aerosol number flux in the surface layer above the canopy. The authors noted: "From 9:30 to 10, the aerosol flux changed sign to rapidly increasing downward fluxes and reached a maximum level from noon until the evening, but with large fluctuations on a time scale of $1-2 h$. The large downward flux during the nucleation event is typical for the nucleation days (87\% of the cases [...]), which supports the concept of an elevated source, above the canopy and the surface layer, for new particles" (Nilsson et al., 2001a, p. 455). Nilsson's findings are closely related to the observations from the micrometeorological NPF characterisation study for the BIOFOR campaign performed by Buzorius et al. (2001). Buzorius et al. (2001, Figs. 4a, 6) observed large particle downward fluxes ("deposition") in the average diurnal course of the particle flux over the event days, indicating an elevated source (with respect to the measurement levels at 23 and $46 \mathrm{~m}$ height, approximately 10 and $33 \mathrm{~m}$ above the forest canopy) of particles larger than $10 \mathrm{~nm}$. The authors found, that on average the turbulence intensity and the heat flux were 
significantly increased, and the temperature and $\mathrm{H}_{2} \mathrm{O}$ vapour concentration were decreased during the event days.

Evaluating carbon dioxide $\left(\mathrm{CO}_{2}\right)$ flux measurements, Buzorius et al. (2001, p. 399) concluded: "Based on the $\mathrm{CO}_{2}$ flux data, no apparent connection between the photosynthetic activity of the forest (a possible indicator of biogenic emissions of precursor gases for nucleation and condensation) and the particle formation occurrence was observed." 6 However, as in the present model biogenic chemistry is neglected, the simulation results can not be directly extrapolated to forest regions. Accompanying $\mathrm{CO}_{2}$ flux measurements can provide valuable help to examine, whether the premises of the model with respect to biogenic processes are complied or not. Deviations from these conditions in boreal forest regions are discussed in Boy et al. $(2003,2005)$ and Hyvönen et al. (2005). Their findings suggest an important role of biogenic compounds in NPF.

Recently, Held et al. (2004) evaluated NPF events observed during the BEWA field campaign in the summers of 2001 and 2002 at the "Waldstein" forest ecosystem research site ${ }^{7}$. Within 45 days of measurement operations during the BEWA campaign, NPF events of varying intensity were observed on 13 days (22\%) (Held et al., 2004, Table 2). Next to particle size distributions, turbulent particle number fluxes were directly measured at a height of $22 \mathrm{~m}$ above ground level (a.g.l.). A typical "banana"-shaped NPF event occurred on 2 August 2001, revealing the onset of NPF through gas-to-particle conversion at 08:15 CET (Held et al., 2004, Fig. 1). On average over the whole campaign, the authors could neither derive a predictive capability from observed meteorological parameters nor find a clear correlation between NPF events and low condensation sink. It was demonstrated, that the observed $\mathrm{H}_{2} \mathrm{SO}_{4}$ vapour concentrations typically explained less than $10 \%$ of the observed growth rates, whereas a significant fraction of particle growth was related to condensation of organic vapours from $\alpha$-pinene oxidation. Hence, in this case biogenic emissions of reactive organic compounds were suspected to play an important role in particle growth during BEWA. Typically, turbulent particle fluxes from the atmosphere to the vegetation dominated at this site, whereas strongest particle deposition fluxes were observed during NPF events. For the NPF event on 2 August 2001 it was shown, that the sudden occurrence of nucleation particles coincided with the onset of particle deposition, reaching a maximum just before noon (Held et al., 2004, Fig. 3).

\footnotetext{
${ }^{6} \mathrm{M}$. Kulmala (personal communication) is thanked for the reference to a more recent study of Kulmala et al. (2004c), according to which there are clear evidences, that photosynthesis has an effect on aerosol formation. This subject will be addressed in more detail in Sections 6 and 7.

7 "Waldstein" forest ecosystem research site: $50^{\circ} 09^{\prime} \mathrm{N}$, $11^{\circ} 52^{\prime} \mathrm{E}, 776 \mathrm{~m}$ a.s.1., "Fichtelgebirge" mountain range in northeast Bavaria, Germany.
}

To explain this observation, the authors considered two hypotheses:

1. At first, particles smaller than the detectable size were formed within the forest stand, i.e., below the flux measuring height. Afterwards, they must have been emitted from the forest, grew up to detectable size above the forest stand and deposited.

2. Emissions from the forest stand contributed to the growth of TSCs (Kulmala et al., 2000) and particles above the forest stand, followed by deposition.

In both cases, nucleation particles are formed, and after subsequent growth into the detectable size range they deposit. A high deposition velocity of UCNs agrees also with theoretical predictions. While flux observations indicated net deposition of UCNs and thus making the forest a sink of particle number, the authors also referred to the observed evolution of the particle size distribution, which supports the occurrence of NPF and growth, suggesting the forest being a source of particulate matter: "Thus the net effect of the forest stand on particle mass remains unclear in this study" (Held et al., 2004, p. 8 of 9). However, even though only in a qualitative way, in the present study it is demonstrated, how observed deposition fluxes can be related to top-down diffusion due to CBL turbulence.

\section{NPF at rural sites}

Birmili et al. (2000, Fig. 1) presented a typical NPF event on 20 April 1998 at Hohenpeissenberg during the HAFEX field study. The daytime evolution of the particle size distribution resembles the typical "banana"-shape pattern. In connection with a synoptic high-pressure ridge and subsiding air, intense solar radiation, strong temperature increase, decrease of relative humidity in the course of the day and low concentrations of pre-existing aerosol particles were observed. After the breakup of the nocturnal boundary layer inversion around 07:30 CET, a temporary increase in $\mathrm{H}_{2} \mathrm{SO}_{4}$, nitric oxide (NO), $\mathrm{SO}_{2}$ and total particle number concentration was observed, thereafter decreasing again. Between 11:00 and 12:00 CET, when the mixed layer was fully developed, a strong increase in UCN and total number concentration was observed. The $\mathrm{H}_{2} \mathrm{SO}_{4}$ concentration reached $1.5 \times 10^{7} \mathrm{~cm}^{-3}$, following the evolution of the $\mathrm{OH}$ concentration. For a two-hour time interval (10:30-12:30 CET), the authors empirically derived an apparent nucleation rate ${ }^{8}$

\footnotetext{
${ }^{8}$ Due to the lower limit of the detectable particle size only an "apparent" nucleation rate can be determined from field measurements. The apparent nucleation rate is the nucleation rate, at which newly formed particles appear in the sensor detection range of $D_{p} \geq 3 \mathrm{~nm}$. When new embryos, i.e., "critical clusters" with $\sim 1 \mathrm{~nm}$ diameter, grow in size by condensation and intra-mode coagulation, their number concentration decreases. As a result, the apparent nu-
} 
of $\sim 3 \mathrm{~cm}^{-3} \mathrm{~s}^{-1}$ from observations, that could not be exceeded using the parameterisation of the binary nucleation rate proposed by Kulmala et al. (1998a). To exceed the observed nucleation rate via binary nucleation, a $\mathrm{H}_{2} \mathrm{SO}_{4}$ concentration of $3 \times 10^{9} \mathrm{~cm}^{-3}$ would be required, which is a few hundred times more $\mathrm{H}_{2} \mathrm{SO}_{4}$ than which was actually observed. Assuming an ambient $\mathrm{NH}_{3}$ mixing ratio of at least $20 \mathrm{pptv}$ in the agricultural environment of Hohenpeissenberg, only $(1-2) \times 10^{7} \mathrm{~cm}^{-3} \mathrm{H}_{2} \mathrm{SO}_{4}$ vapour would be necessary, when applying the ternary nucleation rate of Korhonen et al. (1999). Birmili et al. (2000) concluded, that a ternary nucleation process was responsible for the NPF event observed at Hohenpeissenberg. The authors suggested, that the $\mathrm{NH}_{3}$ concentration was already so high, that the noontime $\mathrm{NH}_{3}$ minimum due to turbulence-induced dilution can not be a limiting factor in NPF. However, as seen from the coincidence of the onset of the NPF burst and the maximum of $\mathrm{H}_{2} \mathrm{SO}_{4}$, the appearance of the NPF burst at forenoon must be photochemically induced. In their study, the $\mathrm{NH}_{3}$ background level served as a time-independent adjustment parameter to get the observed nucleation rate. It is to note, that the secondary UCN peak observed in the morning hours (Birmili et al., 2000, Figs. 1a, b) corresponds well to that appearing in the binary case shown in Fig. 11a of Paper III. Even if the overall UCN evolution pattern corresponds to the binary case simulated in Paper III, the measured $\mathrm{H}_{2} \mathrm{SO}_{4}$ vapour concentration was too low to explain the observed NPF burst by binary nucleation alone.

Later on, the influence of a third component in NPF was also suggested from the evaluation of the long-term HAFEX observation study performed by Birmili et al. (2003, April 1998 to August 2000). The authors considered the question: "Can ternary homogeneous $\mathrm{H}_{2} \mathrm{SO}_{4}-\mathrm{NH}_{3}-\mathrm{H}_{2} \mathrm{O}$ nucleation serve as a model to explain the observed particle formation events at Hohenpeissenberg?" (Birmili et al., 2003, p. 369). On average, the observed nucleation rate was explained by ternary homogeneous $\mathrm{H}_{2} \mathrm{O} / \mathrm{H}_{2} \mathrm{SO}_{4} / \mathrm{NH}_{3}$ nucleation, the observed nucleation mode particle growth by cocondensation of $\mathrm{H}_{2} \mathrm{O} / \mathrm{H}_{2} \mathrm{SO}_{4} / \mathrm{NH}_{3}$. The oxidation products of monoterpenes were suspected to have the capacity to contribute to the growth of UCNs. The ternary nucleation rate was calculated with the nucleation model of Napari et al. (2002a,b) using in situ measured $\mathrm{H}_{2} \mathrm{SO}_{4}$, relative humidity, temperature and an implicitly assumed $\mathrm{NH}_{3}$ mixing ratio of $100 \mathrm{pptv}$. The nucleation rate, calculated near the ground, was compared with the empirically one, derived from in situ

cleation rate is lower than the calculated one from nucleation theory. Kerminen and Kulmala (2002) derived an analytical formula to relate the apparent nucleation rate to the real one. This formula was developed for application in explicit nucleation schemes in atmospheric models to cut off the lowest desirable scale for the evolution of the aerosol size distribution. However, as the authors noted, this formula is not applicable to very intensive NPF bursts, to potential nucleation events associated with cloud outflows or to nucleation occurring in plumes undergoing strong mixing with ambient air. observations (Birmili et al., 2003, Fig. 12a). The experimental formation rates were found to range between 0.01 and $9 \mathrm{~cm}^{-3} \mathrm{~s}^{-1}$, while the ternary rates were scattered across the range $10^{-9}-10^{3} \mathrm{~cm}^{-3} \mathrm{~s}^{-1}$. However, the authors concluded: "Although no remarkable correlation between the two rates was found, the comparison in Fig. 12a leads to the conclusion, that ternary nucleation is, in principle, able to generate the number of fresh nano-particles, that are later observed as particles $>3 \mathrm{~nm}$ " (Birmili et al., 2003, p. 369).

To get more insight into the NPF during HAFEX, the authors investigated the NPF under thermodynamical conditions, prevailing near the top of the boundary layer (TBL) (Birmili et al., 2003, Fig. 12b). The calculated ternary rates were found to be scattered around the experimental formation rates within a few orders of magnitude only. The ternary nucleation rate, predicted near the TBL, may be up to 6 orders of magnitude higher than that near the ground (Birmili et al., 2003, Fig. 13). For the calculation of the nucleation rate at the TBL, $\mathrm{H}_{2} \mathrm{SO}_{4}$ vapour was assumed to be well-mixed across the $\mathrm{CBL}$ and, as before, the $\mathrm{NH}_{3}$ mixing ratio was assumed to be $100 \mathrm{pptv}$. Thus, the enhanced nucleation rate at the TBL mainly reflects the extremely strong non-linear dependency of the ternary nucleation rate on thermodynamical parameters, i.e., on temperature and relative humidity. To think in relative terms, the authors noted right away: "Despite the agreement shown, however, we advocate care in the interpretation of these results, especially in view of the assumptions made on the unknown precursor concentrations near the TBL" (Birmili et al., 2003, p. 370). "Although a large number of precursor gases, aerosol, and meteorological parameters were measured, the ultimate key factors controlling the occurrence of NPF events could not be identified" (Birmili et al., 2003, p. 361). Especially, indications, that reaction products of organic compounds would directly control the occurrence of NPF events, were not found. Apart from this, it was impossible to define a global set of threshold criteria to effectively separate event days and non-event days.

The assumption of an implicit and time-independent upper limit of the $\mathrm{NH}_{3}$ mixing ratio of $100 \mathrm{pptv}$ reduces the modelled UCN number concentration to a NPF process, that is fully controlled by the thermodynamical conditions and the evolution of $\mathrm{H}_{2} \mathrm{SO}_{4}$ vapour, whereas $\mathrm{NH}_{3}$ serves only as a constant adjustment parameter, e.g., comparable to the turbulence-related adjustment factor for the binary nucleation rate derived by Uhrner et al. (2003, Fig. 5) (see below). As $\mathrm{NH}_{3}$ was not considered to be a limiting factor, the observation of an $\mathrm{NH}_{3}$-enhanced nucleation actually does not support the ternary NPF scenario presented in Fig. 11a of Paper III. Birmili et al. (2003, p. 374) pointed out, that the understanding of the occurrence of NPF events is linked to the question, why the particle size distributions were closed at the smallest diameters. They hypothesised either NPF at the CBL top or a non-linear particle growth rate below $3 \mathrm{~nm}$. 
Uhrner et al. (2003) paid special attention to the role of meteorological conditions for the NPF events, occurring during the HAFEX field study. The authors compared measured particle number concentrations and inferred particle surface area concentrations with box model simulations for 12 carefully selected data sets, collected during the HAFEX experiment (Birmili et al., 2003). The aerosol model included a binary nucleation scheme. The calculated nucleation rates were adjusted by a prefactor to match measured and calculated particle number concentrations. This prefactor was physically related to the occurrence of turbulence and parameterised in terms of surface layer stability. The authors concluded, that the NPF process maybe strongly influenced by mixing processes driven by thermal convection and/or wind shear. Among several other HAFEX days, Uhrner et al. (2003, Figs. 2c, 2g, 2k, 2o, 3b, 4) re-evaluated the NPF event on 20 April 1998. In the former study of Birmili et al. (2000, Fig. 1), this NPF event was explained by ternary nucleation at an ambient $\mathrm{NH}_{3}$ mixing ratio of at least $20 \mathrm{pptv}$. To achieve agreement between measured and modelled particle number concentrations, Uhrner et al. (2003) empirically increased the binary nucleation rate by a prefactor of $10^{13}$ for 20 April 1998. The prefactor was iteratively determined by variation until the measured and simulated peak number concentration matched within $\pm 25 \%$. The NPF event on 20 April 1998 was characterised by strong vertical exchange associated with turbulent eddies and plumes. The main increase in observed number concentration $\left(D_{p} \geq 3 \mathrm{~nm}\right)$ was accompanied by a significant reduction in the dew point temperature, likely induced by entrainment of drier air from aloft into the CBL, followed by top-down diffusion. The wellmixed layer reached a height of approximately $750 \mathrm{~m}$ above the measurement site. A strong orographic impact on the flow was ruled out. Uhrner et al. (2003, Fig. 5) found, that the nucleation prefactor strongly depends on the CBL stability in terms of near-surface layer temperature gradients. The prefactor varies over many orders of magnitude and assumes larger values for more unstable conditions. The authors related the good agreement between the observed and the modelled number concentration ( $\geq 3 \mathrm{~nm}$ ) for the NPF event on 20 April 1998 and for similar event days to the influence of vertical exchange processes: "For particle number concentration profiles, where the simulated particle number concentration either rose faster than the measured increase, or where the onset of a sharp rise in particle number concentration occurred before the measured onset, the cause could be related to buoyancy-driven turbulent exchange processes. This indicates, that under convective conditions the initial particle nucleation process occurs higher up in the atmosphere, where

\footnotetext{
${ }^{9}$ Uhrner et al. (2003) motivated this factor by the observed strong CBL turbulence. However, it is only a qualitative hint to the contribution of turbulence to NPF, but not a direct evidence supporting turbulence-related nucleation, because this value is too large (M. Kulmala, personal communication).
}

more favourable conditions occur followed by downward mixing and growth to detectable size. Therefore, a significant part of these differences and their variability is attributed to non-local formation of particles and micrometeorological processes, that cause them to be transported to the groundbased measurement site. Our results suggest, that buoyancydriven turbulence and wind shear are the micrometeorological processes accounting for such transport. [...] To gain further insight into these processes, measurements of, e.g., vertical profiles of quantities characterising turbulent transport processes up to the entrainment layer and $\mathrm{NH}_{3}$ concentrations are desirable" (Uhrner et al., 2003, p. 358).

The study of Uhrner et al. (2003) allows some important conclusions regarding the understanding and description of NPF under convective conditions. The use of a semi-empirical prefactor to adjust the binary nucleation rate to observed CBL turbulence is at least as plausible as the assumption of an implicit time-independent ambient $\mathrm{NH}_{3}$ mixing ratio to get the observed nucleation rates ${ }^{10}$. Hence, in view of the different possibilities to interpret the exemplary HAFEX event day 20 April 1998, i.e., via ternary nucleation (Birmili et al., 2000) or via turbulence-enhanced nucleation (Uhrner et al., 2003), care has to be taken in the interpretation of the observations and the model results. Normally, box models are not able to conclusively explain NPF events in the CBL, independently from the nucleation scheme considered therein. The link between aerosol dynamics and CBL turbulence to explain observed NPF events under convective conditions is a higher-dimensional approach, that explicitly considers transport and entrainment processes. Hence, the considered HAFEX day should be re-investigated using an enhanced modelling approach.

\section{NPF in urban regions}

Combining extensive field measurements during the Pittsburgh Air Quality Study (PAQS) in Pittsburg, Pennsylvania, with an aerosoldynamical and chemical box model assuming ternary $\mathrm{H}_{2} \mathrm{O} / \mathrm{H}_{2} \mathrm{SO}_{4} / \mathrm{NH}_{3}$ nucleation, Gaydos et al. (2005) showed an excellent model-measurement agreement and predictive capability. During a 15 months period, in situ NPF was observed on over 130 days. On 19 out of 19 days with complete data sets available in July 2001, and on 25 out of 29 days in January 2002, the presence or lack of nucleation could be successfully predicted by the ternary nucleation model. The gas phase $\mathrm{NH}_{3}$ concentration used in the nucleation model was derived from total $\mathrm{NH}_{3}$ (gas phase + particle phase) using a thermodynamical equilibrium model. Hence, no implicit, time-independent $\mathrm{NH}_{3}$ level, serving as a free parameter, was assumed. $\mathrm{H}_{2} \mathrm{SO}_{4}$ vapour was demonstrated

\footnotetext{
${ }^{10}$ Both approaches are not conclusive, but at least indicative in view of the great challenge to observe and to model NPF in the PBL.
} 
to be the major condensing compound, i.e., producing particle growth that is similar to the observations. The contribution of other species such as nitrate, ammonium and organic compounds to growth could not be quantified. Anyway, the success of considering $\mathrm{H}_{2} \mathrm{SO}_{4}$ vapour as the sole condensing compound and to neglect the contribution of organics indicated, that the role of organics in NPF and particle growth was probably secondary. The typical NPF event, observed on 11 August 2001, featured a "banana"-shaped particle size distribution, showing a pronounced traffic signal between 07:00 and 08:00 EST, followed by NPF occurring at just after 09:00 EST (Gaydos et al., 2005, Fig. 1). Automobile traffic was the most important local source of UCNs, leading to enhanced concentrations during the morning rush hour between 06:00 and 09:00 EST. As demonstrated, local emissions did not affect the regional NPF events, which usually occur after the morning traffic has decreased to the normal level. Hence, typically observed NPF events were dominated by the regional signal. Most of the NPF events, observed in July 2001, started at about 09:00 EST, just a few hours after sunrise. NPF tended to occur on days with below average $\mathrm{PM}_{2.5}$ concentrations and clear skies and to take place over a large geographic area. The events were observed to sometimes coincide with mixing of the stable night-time groundlevel atmosphere, which supports the hypothesis, that vertical mixing can importantly contribute to NPF. Nevertheless, an important number of NPF events occurring during PAQS was found to not coincide with atmospheric mixing and to occur either earlier or later than the rise of the mixing layer height (MLH). The model was found to generally overpredict the UCN number concentration on NPF event days for both the summer and winter months (2.5 to 4.3 times in July). For one possible reason, the authors referred to the negligence of the dilution connected with the daytime evolution of the MLH. They demanded further investigations to elucidate the observed effect.

With respect to air quality policy, the authors demonstrated, that the NPF frequency is very sensitive against the ammonia concentration. For example, a reduction of ammonia emissions in July by $100 \%$ eliminates all NPF events, while doubling ammonia emissions results in NPF occurring on $89 \%$ of the modelled days. In January, the relation is weaker, the corresponding percentage of NPF events ranging between 24 and $66 \%$.

Anyway, from the results of the PAQS one can conclude, that at least a subset of NPF events observed in Pittsburgh corresponds to the evolution pattern of the binary scenario discussed in Paper III, especially with respect to the mixing hypothesis. In opposite to this, the high number of events explained by in situ ternary nucleation involving $\mathrm{NH}_{3}$ without contribution of turbulent mixing shows, that the scenarios investigated in Paper III do not cover up the range of the real situations leading to NPF events. To open the way for further investigations, Gaydos et al. (2005, p. 5 of 12) noted: "The degree to which vertical transport is important to nucleation in the eastern United States is currently unknown and vertical transport is not included in the box model developed here."

\section{Compilation of previous findings on atmospheric or- ganic aerosol formation}

\subsection{Importance of organic aerosol formation}

Owing to its proposed impact on Earth's climate (Kulmala et al., 2004c), the formation, evolution and physicochemical characterisation of organic aerosols are subjects of ongoing research in the atmospheric research community. Meanwhile, organic aerosol formation belongs to the probably most intensive investigated processes in atmospheric aerosol science. Based on the results of a workshop, which was held at the Hyytiälä (Finland) field station on 10-12 May 2004, Fuzzi et al. (2006) performed a comprehensive assessment study on the current knowledge, terminology and research needs concerning the role of organic aerosols in the atmosphere, climate and global change. In their compilation study, the authors addressed the following issues:

- Relevance of organic aerosol formation for climate change;

- Terminology, i.e., definition of aerosols, degree of volatility of compounds (volatile, semi-volatile, nonvolatile), origin of aerosols (primary, secondary), origin of aerosol components (primary, secondary), age of aerosol particles, composition of aerosols (organic, inorganic, carbonaceous);

- Sources of organic aerosols;

- Formation and transformation of organic aerosols;

- Physical and chemical state of organic aerosols;

- Atmospheric modelling of organic aerosols;

- Outstanding issues for future research on organic aerosols (sources, formation and evolution, physicochemical characterisation, modelling).

Due to the contribution of chemical, aerosoldynamical and meteorological processes on very different time and spatial scales, the model-based "reproduction" of field measurements ${ }^{11}$ is an enormous challenge for state-of-the-art atmospheric models. Despite of great efforts achieved over the last years, our level of process understanding is still too poor to allow a comprehensive model-based explanation of the observations. Regarding the complexity of the processes,

\footnotetext{
${ }^{11}$ Here, "reproduction of observations" means the modelling of data on time and spatial scales, which can be resolved by measurements in a physically meaningful manner.
} 
that are necessary to be considered in organic aerosol formation, Fuzzi et al. (2006, pp. 2031-2032, Section 6) concluded: "The complexity of the processes controlling atmospheric aerosols can only be captured using small-scale, high resolution models which are capable of simulating physical and chemical processes in great detail. These models can yield insight into how perturbations in atmospheric composition and climate might affect organic aerosol formation rates and properties (i.e., sensitivity studies) and the concomitant impacts on aerosol distribution as well as, for example, cloud droplet formation and wet and dry deposition of these aerosols. However this level of chemical and microphysical detail can not be extended to the global scale due to computational limitations, so radiative and climate impacts must be determined using a hierarchy of models from process models over regional models to global scale [...]." The authors referred to about a factor-of-three uncertainty in the direct plus indirect top-of-the-atmosphere radiative effect owing to the representation of organic aerosols in state-of-the-art Chemical Transport Models (CTMs) and Global Climate Models (GCMs) (Fuzzi et al., 2006, p. 2032, reference to IPCC report 2001). Among the processes, which are deserved to be better described in large-scale models, the authors listed also physicochemical subgridscale processes, i.e., processes, that can not be resolved by the applied model grid, and in-atmospheric formation of organic aerosols from gas species. Another subject of high importance is the "lumping" of groups of chemical constituents in model representations. As a prerequisite to achieve further progress, Fuzzi et al. (2006, p. 2033) argued: "Models will ultimately be improved through close collaborations between modellers and those conducting laboratory and field measurements and by investigating $O A$ [organic aerosols] in the context of the full earth system."

\subsection{Compounds contributing to organic aerosol formation}

Atmospheric volatile organic compounds (VOCs) are known to essentially contribute to organic aerosol formation. Such compounds originate from both anthropogenic sources (e.g., aromatics) and biogenic ones (e.g., terpenes), whereas biogenic emissions exceed anthropogenic ones by approximately one order of magnitude (Saathoff, 2003; Lee et al., 2004). Oxidation of VOCs leads to oxygenated compounds with low enough volatility to form secondary organic aerosols (SOAs) via either self-nucleation or gas/particle partitioning on pre-existing aerosols (Lee et al., 2004). SOAs increase atmospheric fine particulate matter and contribute to climate control feedback mechanisms (Kulmala et al., 2004c).

Terpenes, subgroup of VOCs, play an important role in SOA formation. They are widely present in the natural environment, especially in plants as a composition of ethereal oils. Many terpenes are hydrocarbons, but they also occur in oxygenated compounds such as in alcohols, aldehy- des and ketones (terpenoides). The building block of terpenes is isoprene $\left(\mathrm{CH}_{2}=\mathrm{C}\left(\mathrm{CH}_{3}\right)-\mathrm{CH}=\mathrm{CH}_{2}\right.$, i.e., sum formula $\left.\left(\mathrm{C}_{5} \mathrm{H}_{8}\right)_{\mathrm{n}}\right)$. Terpene hydrocarbons are classified according to the number of involved isoprene units $\mathrm{n}$ (monoterpene $n=2$, sesquiterpene $n=3$, diterpene $n=4$, triterpene $n=6$, tetraterpene $n=8$ ). In dependence on plant species, temperature and humidity, forests and other plants mainly emit isoprenes $\left(\mathrm{C}_{5} \mathrm{H}_{8}\right)$, monoterpenes $\left(\mathrm{C}_{10} \mathrm{H}_{16}\right)$ and sesquiterpenes $\left(\mathrm{C}_{15} \mathrm{H}_{24}\right)$ into the atmosphere (Saathoff, 2003). Together with methane and isoprenes, terpenes are the organic compounds with the highest global emission (linuma et al., 2004). SOAs are formed, e.g., due to heterogeneous reactions of terpenes with $\mathrm{OH}$, ozone $\left(\mathrm{O}_{3}\right)$ and the nitrate radical $\left(\mathrm{NO}_{3}\right)$. The most relevant terpenes for SOA formation are monoterpenes (e.g., $\alpha$-pinene, $\beta$-pinene, $\Delta^{3}$-carene, camphene, limonene, sabinene, mycrene, ocimene, linalool) and sesquiterpenes (e.g., caryophyllene).

Terpene reaction products are, e.g., pinonaldehyde, pinonic acid, nor-pinonic acid, pinic acid, dicarboxylic acids, hydroxy-pinonaldehydes, hydroxy-pinonic acids, dihydroxycarbonylpinanes, dihydroxylpinane nitrates. Monoterpenes contribute to $78 \%$, sesquiterpenes to $22 \%$ of the biogenic SOA mass production (Chung and Seinfeld, 2002; Bonn et al., 2004). The annual monoterpene emission is ten times larger than the annual sesquiterpene emission (Guenther et al., 1995; Bonn et al., 2004), but aerosol formation by sesquiterpenes is more efficient (Hoffmann et al., 1997; Bonn and Moortgat, 2003; Bonn et al., 2004). Some gas phase reactions of terpenes form large molecules in high enough concentration to participate in particle self-nucleation. Others, such as semi-volatile products, may not self-nucleate, but can partition onto existing particle surfaces (Kamens and Jaoui, 2001).

6.3 Compilation of spatio-temporal occurrence of organic aerosol formation in different parts of Earth's atmosphere

\subsubsection{Organic aerosol formation in maritime air}

Kawamura et al. (2003, Table 1) observed homologous series of water-soluble dicarboxylic acids in tropospheric aerosols over Eastern Asia/Pacific region, where oxalic acid was most abundant, followed by malonic or succinic acid. Diacid carbons were found to contribute to $0.2-3.3 \%$ (average $1.8 \%$ ) of the total organic carbon. The water organic acids either stem from ground sources and/or photochemical production in the polluted troposphere over the Asian Pacific.

Narukawa et al. (2003) evaluated free-tropospheric measurements of low-molecular weight dicarboxylic acids over the western to central North Pacific Ocean. The main characteristics of dicarboxylic acids can be summarised as follows (Narukawa et al., 2003, see references therein): (a) Dicarboxylic acids directly originate from emissions from fossil fuel combustion and biomass burning; (b) Dicar- 
boxylic acids are oxidation products of aromatic hydrocarbons and alkenes; (c) Dicarboxylic acids are one of the most abundant water-soluble organic compounds in atmospheric aerosols; (d) Dicarboxylic acids are ubiquitous aerosol constituents in the urban, suburban and marine atmosphere as well as in polar regions of the Arctic and Antarctic; (e) Dicarboxylic acids contribute to cloud condensation nuclei (CCNs) and hydrophilic properties; (f) As soluble organics contribute more to aerosol volume than to aerosol mass due to their lower densities, they can affect direct radiative properties. The authors presented measured concentrations of four dicarboxylic acids, i. e., oxalic acid, malonic acid, adipic acid and azelaic acid as a function of height and longitude (Narukawa et al., 2003, Tab. 2, Figs. 2, 3, and 4). Oxalic acid was found to be the most abundant diacid over the North Pacific Ocean, measured in heavily polluted air mass flows over the ocean, originating from both primary emissions from the large industrial cities of Eastern Asia and secondary photochemical processes. The authors also extrapolated the surface concentration of diacids and the corresponding scale heights (2.9 km for oxalic acid, $2.5 \mathrm{~km}$ for malonic acid, $7.8 \mathrm{~km}$ for adipic acid, $2.2 \mathrm{~km}$ for azelaic acid) (Narukawa et al., 2003, Table 4). The scale heights were found to be higher than that proposed in the literature for desert regions. This indicates a higher extent of air pollutants due to enhanced atmospheric convection and injection of diacids and their precursors from the ground level to the upper troposphere in Eastern Asia (Narukawa et al., 2003). Narukawa et al. (2003) concluded, that (1) diacids in the free-tropospheric aerosol over the western North Pacific Ocean result from Eastern Asia outflows and originate not from the open ocean, (2) these diacids and their precursors originate from ground sources in Eastern Asia and were transported to the upper troposphere by enhanced convection.

\subsubsection{Organic aerosol formation in continental air on a large and global scale}

From their large-scale modelling study of organic aerosol formation over continental Europe, Andersson-Sköld and Simpson (2001) found, that (a) organic aerosol formation is much greater from biogenic sources than from anthropogenic ones, and that (b) monoterpenes play a very variable role in contributing to organic carbon mass in aerosols over the Nordic countries. Corresponding to the relative distribution of forests, the contribution of monoterpenes lies in the range $2-50 \%$, least at coastal sites in Southern Norway and Denmark and much greater for more inland sites and further North. Averaged over all sites and months, the relative contribution of different terpenes to organic aerosol formation was estimated as follows: $\alpha$-pinene $23.5 \%$, limonene $21.3 \%$, sabinene $12.9 \%$, caryophyllene $12.4 \%, \Delta^{3}$-carene $8.1 \%, \beta$-pinene $7.9 \%$, myrcene $4.3 \%$, ocimene $3.9 \%$, linalool $3.6 \%$, camphene $2.1 \%$ (AnderssonSköld and Simpson, 2001, Fig. 6). However, the authors pointed out, that there are large uncertainties in the results, e.g., due to the negligence of important primary sources of organic carbon, notably heavy plant waxes. Further progress requires, in the first order, more measurements to characterise the ambient organic aerosol and more inventory data (Andersson-Sköld and Simpson, 2001, verbatim).

From a global-scale modelling study on $\alpha$-pinene oxidation, Bonn et al. (2004, Table 1) found, that large hydroperoxides, although currently neglected in aerosol models, account for $63 \%$ of SOA mass formation. Carboxylic acids and carbonyl compounds, assumed to be the primary SOA forming substances, account for only $26 \%$ of SOA mass formation. The dominating contribution of hydroperoxides to relative SOA production is most pronounced during the northern hemispheric wintertime owing to the reduced temperature and the decreased photolysis of hydroperoxides, which prolongates their lifetime. The highest total aerosol mass contribution is correlated with the highest monoterpene emissions during summertime. The acid contribution (maximum 33\%) and contribution by peroxy acetyl nitrates (PANs) (maximum $22 \%$ ) are largest during the northern hemispheric summertime due to intense oxidation by $\mathrm{OH}$ (production of monocarboxylic acids) and enhanced photolysis (formation of PAN type species). PAN contributions were especially high for industrialised regions of North America and Europe. The contribution of dicarboxylic acids, commonly considered as a major SOA source, was found to be fractionally highest during spring and autumn (maximum 2.5\%) due to increased $\mathrm{O}_{3}$ and lower $\mathrm{OH}$ level, favouring higher contributions of $\alpha$-pinene ozonolysis (Bonn et al., 2004, p. 2). After condensation, hydroperoxides undergo particle phase and cloud droplet reactions with $\mathrm{OH}$, resulting in aerosol ageing and formation of less water-soluble products, such as carbonyl compounds (e.g., pinonaldehyde from $\alpha$-pinene reactions). Carbonyl compounds, formed inside aerosols and cloud droplets, can be dissolved in the pre-existing organic material and remain in the particle phase in addition to acid catalysis reactions, which form non-peroxide polymers from volatile, soluble carbonyls. Even if these carbonyls are too volatile to condense directly, they can take part in heterogeneous reactions with hydroperoxides to form peroxyhemiacetals in the particle phase. Therewith, large hydroperoxides and especially hydroxy-hydroperoxides increase the amount of organic aerosol formed as well as the solubility of atmospheric organic aerosol particles in water, which leads to an increased CCN number (Ziemann, 2002; Bonn et al., 2004).

\subsubsection{Organic aerosol formation in urban air}

Strader et al. (1999) observed organic aerosol formation due to oxidation of aromatics in wintertime condition with clear skies, low winds and low MLHs in urban and background sites of the San Joaquin Valley of California. Low wintertime MLHs were found to favour the accumulation of precursors, hence accelerating organic aerosol formation. Clouds and fog 
considerably decrease the organic aerosol concentration. Organic aerosol formation undergoes a significant diurnal variation with higher values in the late afternoon and early evening (Strader et al., 1999, Fig. 6). The authors found a strong dependence on temperature, whereas an optimal temperature for organic aerosol formation exists. The optimal temperature results from two competing processes: (a) Increase of organic aerosol formation with increasing temperature; (b) Increase of the saturation vapour pressure with increasing temperature (i.e., decreasing supersaturation and decrease of organic aerosol formation).

Using a 3D Eulerian model, Andreani-Aksoyoglu et al. (2004) investigated organic aerosol formation in the northern part of the Po Basin, one of the most densely populated and strongly industrialised areas in Europe. Even if organic aerosols contain both primary and secondary organic aerosols, the primary ones were not included in their study, because no emission data were available. As in the case of $\mathrm{O}_{3}$, highest secondary organic carbon (SOC) concentrations were modelled to occur in the afternoon in the photochemically active city plume of Milan. The modelled similarity between the SOC distribution and that of $\mathrm{O}_{3}$ was found to result from the fact, that organic aerosols are formed by the mass transfer to the particle phase of low-vapour pressure products of VOC oxidation. From measurements of the concentrations of total organic carbon (TOC $\equiv$ primary organic carbon (POC) plus SOC) and black carbon (BC), Andreani-Aksoyoglu et al. (2004, Fig. 7) derived a ratio $\mathrm{POC} / \mathrm{BC}=1.8$. $\mathrm{BC}$ originates from combustion processes and is solely primary. Assuming, that $\mathrm{BC}$ and $\mathrm{POC}$ are from the same source, BC can be used as a tracer of POC. For the concentration of SOC, Andreani-Aksoyoglu et al. (2004, Table 1) proposed the relation $\mathrm{SOC}=\mathrm{TOC}-1.8 \times \mathrm{BC}$.

The most relevant anthropogenic precursors of organic aerosol formation are aromatics, the most important biogenic ones are biogenic hydrocarbons such as monoterpenes. The contribution of biogenic emissions to organic aerosol formation is of increasing interest. This contribution depends, e.g., on the season and on the urbanity of the region of interest, which reflects the vegetation coverage. On the base of a May case study the authors demonstrated, that monoterpene emissions contribute to about $25 \%$ to organic aerosol formation in the northern, mostly forested part of the model domain, while in the southern, mainly urban, and agricultural part its contribution is negligible. Altogether, the agreement between estimated and predicted SOC concentrations was found to be satisfactory, i.e., the predicted values were of the same order of magnitude as the estimated ones. Observed differences to other studies for European regions were related to discrepancies in the emission inventories and to differences in the aerosol parameterisation.

\subsubsection{Organic aerosol formation in forest regions}

Papers addressing organic aerosol formation in forest regions were presented, e.g., by Mäkelä et al. (1997), Marti et al. (1997), Kavouras et al. (1998), Kulmala et al. (1998b, 2000), Buzorius et al. (2001), Kulmala et al. (2001a,b), Boy and Kulmala (2002b), Dal Maso et al. (2002), Kulmala et al. (2002), Boy et al. (2003), Buzorius et al. (2003), Komppula et al. (2003a,b), Krejci et al. (2003), Kulmala (2003), Held et al. (2004), Hellén et al. (2004), Kulmala et al. (2004a,b,c), Laakso et al. (2004a,b), Steinbrecher and the BEWA2000Team (2004), Boy et al. (2005), Dal Maso et al. (2005), Hyvönen et al. (2005), Kulmala et al. (2005a), Sellegri et al. (2005b,a), Allan et al. (2006), Cavalli et al. (2006) and Kulmala et al. (2006).

From a NPF study on a forested ridge in the Rocky mountains, Marti et al. (1997) found, that organics formed from oxidation of naturally occurring terpenes $\alpha$ - and $\beta$-pinene and anthropogenic hydrocarbons toluene, $m$-xylene, ethyl benzene, 1,2,4 trimethyl benzene and methylcyclohexane are well correlated with total particle surface area and volume. This suggests, that some of the organic compounds, formed in gas phase reactions, condensed upon pre-existing aerosols. However, NPF was reported to be more associated with elevated production of $\mathrm{H}_{2} \mathrm{SO}_{4}$ vapour from $\mathrm{SO}_{2} / \mathrm{OH}$ oxidation than with production of oxidised organic products. There are also evidences, which support the involvement of terpene species in NPF for $\mathrm{H}_{2} \mathrm{SO}_{4}$ production and below-average total aerosol surface area. $\mathrm{H}_{2} \mathrm{SO}_{4}$ was supposed to be the key precursor for NPF. Low-volatility organic compounds were considered to be able to cause NPF under certain conditions, but are more likely to condense upon preexisting particles.

Kavouras et al. (1998) observed NPF over a Eucalyptus globulus forest. Newly formed aerosols were found to contain both a major carbonyl fraction and an acidic fraction. The carbonyl fraction consists of pinonaldehyde and nopinone from photooxidation of $\alpha$ - and $\beta$-pinene. Besides of plant leaf wax $n$-alkonic acids, the acidic aerosol fraction contained carboxylic acids (pinonic acid), formed primarily by the $\alpha$-pinene/ $\mathrm{O}_{3}$ photooxidation. All pinonic acids together were found to be more abundant than plant leaf wax $n$-alkonic acids in the acidic aerosol fraction. Pinonic acids are only accumulated on particles $<500 \mathrm{~nm}$, leaf wax $n$ alkanoic acids only on particles $>500 \mathrm{~nm}$. Being too volatile, observed formic acid from isoprene/terpene photooxidation and acetic acid were reported not to contribute to NPF. Pinonaldehyde and nopinone concentrations were found to be low during daytime due to photolysis and/or reaction with $\mathrm{OH}$ and to increase during night due to $\alpha$ - and $\beta$-pinene reactions with $\mathrm{NO}_{3}$ and/or $\mathrm{O}_{3}$. The presence of the two carbonyl compounds in particulate matter is supposed to result from condensation of vapour phase products onto preexisting seed particles. Once organic compounds have started to condense and an organic layer has formed on the par- 
ticles, even products with subsaturated gas phase concentration will partition a portion of their mass into this condensed organic phase. This process is favoured by lower night-time temperatures. Thus, NPF over forests is supposed to be caused by interaction of organic acids, e.g., pinonic acid from terpene-photooxidation, with other organic or inorganic species present in the atmosphere (Kavouras et al., 1998).

Steinbrecher and the BEWA2000-Team (2004) reported on the quantification of soil and leaf primary emissions and the canopy exchange (net emission and net deposition) of gases (isoprenoids, carbonyls, peroxides, $\mathrm{O}_{3}$ ) and particles at the Norway spruce forest field site Waldstein, Fichtelgebirge, north-east Bavaria, Southern Germany. In a regional-scale modelling study on the emissions of biogenic volatile organic compounds (BVOCs) over Germany, Steinbrecher and the BEWA2000-Team (2004) estimated a yearly averaged VOC emission from forests of $366 \mathrm{kt}$ for Germany, with contributions of $11 \%$ isoprenes, $51 \%$ monoterpenes and $38 \%$ other VOCs. Norway spruce as the main emitting tree species contributes with $40 \%$. In situ photosynthesis was found to be a major carbon source for the isoprenoid synthesis in plants. It was shown, that the short-term variability of the isoprene emissions is controlled by the flux of photosynthetic intermediates through the plastidic isoprenoid pathway. Under $\mathrm{CO}_{2}$ limiting conditions, isoprenoid biosynthesis may serve as a sink for primary products of net-photosynthesis. Next to in situ photosynthesis also other C-sources were found to contribute to the isoprene formation, e.g., starch, xylem transported carbohydrates, especially under conditions of reduced net $\mathrm{CO}_{2}$ assimilation due to the closure of the stomata. The authors concluded, that there is a dynamic exchange of $\mathrm{C}$ between different cellular precursors for isoprene biosynthesis. They showed the increasing importance of these $\mathrm{C}$ pools, when the photosynthesis is limited. Daily summertime time series of particle fluxes above the canopy showed a typical diurnal pattern, which results from the boundary layer dynamics, from regional atmospheric processes (e.g., atmospheric $\mathrm{O}_{3}$ production) and from primary emission and deposition. Sometimes, the measurements were influenced by horizontal advection of air masses over horizontally inhomogeneous forests. For isoprenoids, the leaf level fluxes were found to agree well with ecosystem level fluxes. The measurements revealed the occurrence of many oxidation products of isoprenoids in the forest atmosphere with higher concentrations during daytime. Particles from above the canopy were observed to have an enhanced pinic acid concentration, supposed to result from in situ photochemical formation, e.g., from the reaction of $\alpha$-pinene with $\mathrm{O}_{3}$. Turbulent particle fluxes often followed a diurnal pattern with almost no particle exchange at night and strong fluxes during daytime. During daytime, the particle deposition flux clearly dominated over the emission fluxes. The strongest deposition fluxes in the order of $10^{8}$ particles $\mathrm{m}^{-2} \mathrm{~s}^{-1}$ occurred during NPF events. NPF events showed a characteristic evolution of the particle size distribution, with growth rates in the range
$2-6 \mathrm{~nm} \mathrm{~h}^{-1}$. Calculations confirmed, that oxidation products of BVOCs considerably contribute to the observed condensation growth. Accompanying modelling studies showed, that the BVOC loss within the forest canopy due to chemical degradation ranged between 10 to $15 \%$ of the total emitted BVOCs. BVOC degradation by the $\mathrm{NO}_{3}$ radical is likely to proceed also during daytime in shaded lower parts of the canopy.

\section{Synopsis of the meteorological and physicochemi- cal conditions leading the organic aerosol formation in forest regions - compilation of phenomenological findings}

\subsection{Findings from the EU project OSOA (Origin and For-} mation of Secondary Organic Aerosol)

A comprehensive overview of the results from extensive field measurements concerning the origin and formation of organic aerosol formation in forest regions was given by Boy et al. (2004). The measurements were carried out at the Finnish measurement station Hyytiälä between 1 and 16 August 2001 within the framework of the EU project $\mathrm{OSOA}^{12}$. A possible NPF pathway to form organic aerosols in the atmosphere is the ternary $\mathrm{H}_{2} \mathrm{O} / \mathrm{H}_{2} \mathrm{SO}_{4} / \mathrm{NH}_{3}$ nucleation to form TSCs (diameter $\approx 1 \mathrm{~nm}$ ) according to Kulmala et al. (2000). The authors suggested, that ternary nucleation occurring at typical tropospheric conditions is able to accumulate a reservoir of TSCs, which further grow to detectable sizes under favourable conditions. According to this model, organic species with low volatility could act as condensable vapours for the condensation growth of TSCs to an observable size of $D_{p}=3 \mathrm{~nm}$. Some of the main results of the OSOA project can be summarised as follows (Boy et al., 2004):

- The observed NPF events showed a clear decrease of the condensation sink (denoted as $C S$, i.e., the loss of condensable molecules to the pre-existing aerosol with molecular properties taken for $\mathrm{H}_{2} \mathrm{SO}_{4}$ ) shortly before or at the beginning of the burst, which results from the

\footnotetext{
${ }^{12}$ SOAs are formed, when the saturation vapour pressures of the precursor gases are low enough to condense them on pre-existing aerosols or to initiate NPF via homogeneous nucleation. Previous findings from the literature indicate aerosol formation and growth from the reaction products of $\alpha$-pinene and $\mathrm{O}_{3}$, that could not be explained by classical nucleation theory. The nucleation rate in the $\alpha$-pinene $/ \mathrm{O}_{3}$ system is suspected to be limited by initial nucleation steps (i.e., dimer, trimer or adduct formation). SOA formation in the $\alpha$-pinene $/ \mathrm{O}_{3}$ system is considered to be a possible pathway for NPF by homogeneous nucleation from organic species, which result from gas phase reactions involving monoterpenes. However, SOA formation from this system was only observed under laboratory conditions with $\alpha$-pinene concentrations one order of magnitude higher than those observed under atmospheric conditions (Boy et al., 2004, see references therein).
} 
onset of turbulence and the growth of the mixed layer (mixing of relatively clean residual layer air with more polluted surface layer air). The values of the condensation sink on NPF event days at the beginning were on average smaller $\left(C S \approx 0.001 \mathrm{~s}^{-1}\right)$ than on the other days $\left(C S \approx 0.002-0.003 \mathrm{~s}^{-1}\right)$. It was clearly demonstrated, that high number concentrations of pre-existing aerosols reduce or prevent NPF due to the large sink for condensable vapours or due to the very small newly formed particles below $3 \mathrm{~nm}$.

- The growth rate of the newly formed particles during the early stages (first few hours) of growth was found to range in the interval $6-11 \mathrm{nmh}^{-1}$, the range of the vapour concentration was observed to be $(8-15) \times 10^{7} \mathrm{~cm}^{-3}$ and that of the source rates to be $(1-5) \times 10^{5} \mathrm{~cm}^{-3} \mathrm{~s}^{-1}$.

- The ambient aerosol in Hyytiälä was found to be quite inert with respect to water uptake.

- As characteristic features, occurring on all NPF events during the bursts, rapid increase in particle concentration together with very large downward particle number fluxes ${ }^{13}$ in the range $(30-70) \times 10^{6}$ particles $\mathrm{m}^{-2} \mathrm{~s}^{-1}$ were observed. The very high flux values during the NPF events resulted from elevated particle number concentrations and from the domination of small nucleation mode particles in the size spectrum, having very high deposition velocities ${ }^{14}$.

- Boy et al. (2004) found indications for NPF occurring throughout the PBL in a more or less homogeneous pattern.

- Although $\mathrm{SO}_{2}$ or its oxidation product $\mathrm{H}_{2} \mathrm{SO}_{4}$ is suspected to be involved in the TSC formation via binary/ternary nucleation, other parameters such as the number concentration of pre-existing aerosols were considered to be probably more important for NPF than $\mathrm{SO}_{2}$ under atmospheric conditions.

- Boy et al. (2004) did not found observational evidences for a direct correlation of the precursor gas concentration of monoterpenes, inclusive their photooxidation products, with the lowest saturation vapour pressure (carboxylic acids) and the nucleation mode number concentration. The question, whether homomolecular or

\footnotetext{
${ }^{13}$ The aerosol particle number fluxes represent fluxes of particles with $D_{p}>10 \mathrm{~nm}$. The fluxes were measured at a height of $23 \mathrm{~m}$, approximately $10 \mathrm{~m}$ above the forest canopy.

${ }^{14}$ In addition, significant flux variations could also be caused by horizontal advection and CBL circulation. Boy et al. (2004) emphasised, that the observed particle fluxes during NPF events result from vertical motions of small particles, i.e., deposition of small aerosols into the forest, which implies the occurrence of higher particle concentrations up in the CBL.
}

heteromolecular homogeneous nucleation of unknown organic species does occur in the atmosphere, is not yet answered. However, there were high enough concentrations of organic compounds with very low saturation vapour pressure, which can serve as condensing species on TSCs during the time of NPF bursts. In any case, a clear contribution of organic matter originating from the oxidation of terpenes from the local biosphere could be recognised.

- On average, the relative humidity was found to be lower during NPF bursts or to be low prior to the NPF onset. On NPF event days, bursts were observed to occur after the short wavelength irradiance (SWR, 300$340 \mathrm{~nm}$ ) exceeding $6 \mathrm{~W} \mathrm{~m}^{-2}$. Considering the time a TSC needs to grow to a detectable size ( $\sim 20 \mathrm{~min})$, NPF was expected to start at all event days during the ascending part of the irradiance curve. The estimated NPF start time was found to coincide with the onset of vertical wind variance, i.e., the start of mixing of different air masses from the residual and the surface layer (Boy et al., 2004, verbatim). NPF was found to occur in relatively clean and cold air, passing over the station from the north-west (arctic air masses, sometimes polar air masses, preference of air masses in transition from marine to continental air masses).

- From observational data obtained at the SMEAR II station Hyytiälaä during 2000 and 2001, Boy and Kulmala (2002b, Fig. 9, Production rate of excited oxygen $\mathrm{O}\left({ }^{1} \mathrm{D}\right)$ for 28 May 2000) demonstrated, that the SWR is the most important solar spectral radiation for NPF or for the growth of new clusters to detectable size. The authors suggested a high possibility of excited oxygen atoms and $\mathrm{OH}$ radicals to be involved in the production of vapours contributing to NPF. Most of the NPF event days, especially during winter, showed very high values of the excited oxygen production rate compared to non-NPF event days in the same month.

7.2 Compilation of statistical findings from long-term observations

Boy et al. (2003) evaluated measurements from the Hyytiälä field site during 2000-2001 to provide long-term statistics of NPF characteristics. Main results can be summarised as follows:

- During 2000-2001, the authors observed 29 NPF events with high formation rates of $3 \mathrm{~nm}$ particles and subsequent growth to larger particle sizes, 45 NPF events showing the same behaviour with less clarity and 57 marginal NPF events, where one of the two criteria was not clearly observed. Nearly all NPF bursts started after sunrise. The time difference between sunrise and nucleation start was found to be smaller in spring compared 
to summer and autumn throughout the two years and the duration of the bursts to be longer during the spring events (in 2000-2001 40\% of all NPF events occurred during March-May).

- NPF was found to mostly occur on days with low number concentrations of pre-existing particles $\left(N_{50-100}<1000 \mathrm{~cm}^{-3}\right)$, as seen from the anticorrelation between the number concentration of newly formed particles with $D_{p}=3-6 \mathrm{~nm}$ and the condensation sink $C S$ for particles with $D_{p} \geq 3 \mathrm{~nm}$. Most of the NPF event days were associated with negative, i.e., downward-directed particle fluxes.

- On pronounced event days in May 2000, NPF was associated with maxima of the vertical velocity variance $\left(\overline{w^{\prime} w^{\prime}}\right)$, but in autumn, no difference in $\overline{w^{\prime} w^{\prime}}$ between NPF event and non-event days could be detected. On clear days, the $\overline{w^{\prime} w^{\prime}}$ was observed to depend on solar irradiance, which forces buoyancy-driven CBL development. Most of the NPF event days occurred on sunny cloudless days. Therefore, Boy et al. (2003) concluded, that the high correlation between $\overline{w^{\prime} w^{\prime}}$ and the appearance of NPF bursts could be a by-effect of high solar irradiance on most of the NPF event days. However, a correlation between the daily mean of turbulent kinetic energy and NPF seems to exist.

- The SWR was confirmed to be a key parameter for $\mathrm{NPF}$, as seen from the highest among other parameter correlations with NPF bursts. In early spring and late autumn, all NPF event days were associated with enhanced SWR with respect to the average of the corresponding month. The way, that SWR influences NPF is suspected to be twofold: (1) Dominance of buoyancy forcing in driving the CBL evolution on cloudless, calm days associated with enhanced turbulent kinetic energy and mixing of preloaded surface layer air with clean residual layer air; (2) Photochemical production of $\mathrm{OH}$ during daytime in the lower troposphere. The latter is confirmed by the observed high correlation of the $\mathrm{OH}$ radical with NPF events. The $\mathrm{OH}$ radical reacts with VOCs to form products with very low vapour pressures, e.g., carboxylic acids (Boy et al., 2003, see references therein).

- $\mathrm{H}_{2} \mathrm{O}$ vapour was found to be anti-correlated with NPF. The daily average $\mathrm{H}_{2} \mathrm{O}$ concentration was usually below $2 \times 10^{17} \mathrm{~cm}^{-3}$ during the high-frequency NPF period March-May. The authors safely concluded, that the ambient $\mathrm{H}_{2} \mathrm{O}$ vapour concentration is a limiting factor of NPF.

- The temperature was found to be only weakly correlated with NPF. The influence is expected to result from the direct connection with solar radiation.
- The monoterpene concentration measured at noontime was observed to be anti-correlated with the number concentration of particles with $D_{p}=3-6 \mathrm{~nm}$. The abundance of VOC precursor gases is probably not the limiting factor for NPF to occur.

$-\mathrm{O}_{3}$ is known to be involved in the formation of condensable species via its reaction with monoterpenes. It is suspected to contribute to the SOA formation in late winter and spring. On a single-day basis, no correlation of the $\mathrm{O}_{3}$ concentration with the number concentration of particles with $D_{p}=3-6 \mathrm{~nm}$ could be found, i.e., increasing as well as decreasing $\mathrm{O}_{3}$ concentration can occur on NPF event days.

- Both $\mathrm{SO}_{2}$ and nitrogen oxides were observed to be not correlated with the number concentration of small particles, because both gases are mainly of anthropogenic origin and are mostly associated with high number concentrations of pre-existing aerosols, representing polluted conditions.

- Using precursor and aerosol measurements, Boy et al. (2003) derived the condensing vapour source rate, the concentration of condensable vapour, the growth rate, the apparent nucleation rate and the number concentration of small, non-detectable particles below $3 \mathrm{~nm}$ ( $N_{1-3}$, assuming a critical TSC size of $1 \mathrm{~nm}$ in diameter). All aerosol parameters, i.e., source rate and concentration of condensable vapours and particle diameter growth rate, calculated for the precursor gas $\mathrm{H}_{2} \mathrm{SO}_{4}$, were found to be of the same order of magnitude as those, calculated for the sum of the monoterpene reactions with $\mathrm{O}_{3}$ and $\mathrm{OH}$ (Boy et al., 2003, Table 2). The contributions of the carboxylic diacid molecules to the source rate, the concentration and growth rate in comparison to $\mathrm{H}_{2} \mathrm{SO}_{4}$ molecules were found to be 99,122 , and $124 \%$, respectively.

- The number concentrations of newly formed particles below $3 \mathrm{~nm}$ were estimated to be at least 2-3 times higher than those measured between 3-6 nm. In quantifying the relative importance of loss due to condensation growth, coagulation and deposition, coagulation was found to be the dominating loss term, contributing between 12 and $29 \%$ to the $N_{3-6}$ balance for all NPF events (Boy et al., 2003, Table 5). On pronounced NPF event days, coagulation loss was estimated to be less than half of the values compared to the less pronounced NPF event days, which indicates the presence of low polluted air masses during these days.

- Although the exact condensing vapours remain to be identified, the calculations performed by Boy et al. (2003) clearly demonstrated the dramatic impact, that organic vapours may have on the main aerosol characteristics. The authors concluded, that the concentrations 
of the supposed condensable vapours (carboxylic diacid and $\mathrm{H}_{2} \mathrm{SO}_{4}$ ) were high enough to explain the formation of newly formed particles at $D_{p}=3 \mathrm{~nm}$, but were approximately $40 \%$ too low to account for the growth rates, observed during NPF events in Hyytiälä. Hence, other organic or inorganic molecules were suspected to contribute to the growth process after the particles reached a size of $3 \mathrm{~nm}$ (Boy et al., 2003). The authors found the overall contribution of diacid molecules to the growth rates ranging from $8-50 \%$.

More recently, Hyvönen et al. (2005) reported on results of a comprehensive long-term evaluation study on aerosol formation in a boreal forest using data mining techniques. The dataset was collected over 8 years (1996-2003) at the SMEAR II station. The main result is, that the most important variables in explaining the NPF events are the means of relative humidity $(R H)$ and the logarithm of the condensation sink $(C S)$. On this base, an expression for the "probability of having an event day" $P_{\text {nuc }}$ was proposed, which is anti-correlated with $C S$ and $R H$ (Hyvönen et al., 2005, Eq. (1) $)^{15}$. With respect to the influence of the relative humidity, the authors argued as follows (Hyvönen et al., 2005, p. 3353):

1. Relative humidity forces present particles to grow by uptake of water molecules, which leads to an increase of the available surface area for condensable vapours. Consequently, relative humidity and condensation sink are correlated.

2. Relative humidity and solar radiation reaching the PBL are anti-correlated owing to the strong correlation of relative humidity with cloudiness, fog and rain, that can effectively damp the radiation. The reduction of radiation has a damping effect on photolytic gas phase reactions. Such chemical reactions are an important source of condensable vapours.

3. The $\mathrm{OH}$ production depends on the amount of solar radiation and on the available amount of $\mathrm{H}_{2} \mathrm{O}$

15 Low condensation sink values are known to favour nucleation for two basic reasons (Hyvönen et al., 2005, p. 3352-3353, verbatim, see reference to Kulmala et al. (2005b)):

- "The existing aerosol population depletes the ambient air of vapours by acting as a condensation surface; if the sink is high, no vapour is available to grow the particles to larger sizes, and they are lost by coagulation and deposition. It is also possible that these vapours participate in the nucleation process itself."

- "A higher condensation sink signifies also a higher coagulation rate of newborn particles, meaning a shorter lifetime of these particles. The loss rate due to coagulation is higher the smaller the particle is. Thus, a lower sink increases the likelihood of a nucleated particle growing large enough to survive." vapour. Both parameters increase the $\mathrm{OH}$ concentration. As $\mathrm{H}_{2} \mathrm{O}$ vapour and solar radiation are anticorrelated, there is a maximum $\mathrm{OH}$ production level between low relative humidity (high radiation) and high relative humidity (low radiation): Increasing relative humidity will first result in an increase of $\mathrm{H}_{2} \mathrm{SO}_{4}$ formation, but this will decline after the appearance of clouds (higher relative humidities).

4. The reaction of mono- and sesquiterpenes, originating from biogenic emissions, with $\mathrm{O}_{3}$ leads to the production of very low-volatility substances, that can either (a) condense on clusters and thus activating them by growing to detectable size or (b) directly form new particles. In the first step of the reaction of biogenic terpenes with $\mathrm{O}_{3}$, SCIs are formed, which are suspected to play a key role in homogeneous nucleation of SOAs (Berndt et al., 2003; Bonn and Moortgat, $2003)^{16}$. While monoterpene reaction products were found to be unlikely to form SOAs (Berndt et al., 2003; Bonn and Moortgat, 2003), Bonn and Moortgat (2003) showed, that the sesquiterpene-ozonolysis can cause very intensive NPF events owing to the very high reactivity of sesquiterpenes with $\mathrm{O}_{3}$. Because of the low saturation vapour pressure of the reaction products, the sesquiterpene-ozonolysis is supposed to initiate biogenic SOA formation. In a progressive stage, more volatile reaction products such as from monoterpene reactions (e.g., dicarboxylic acids) will contribute to the particle growth. The most abundant sesquiterpene at nearly all atmospheric conditions is $\beta$-caryophyllene (Bonn and Moortgat, 2003).

7.3 $\mathrm{H}_{2} \mathrm{SO}_{4}$ vapour closure study - Results from the EU project QUEST (Quantification of Aerosol Nucleation in the European Boundary Layer)

Direct observations of precursor gases for NPF, such as $\mathrm{H}_{2} \mathrm{SO}_{4}$ and $\mathrm{NH}_{3}$, are still very rare. To determine the concentration of some important precursor gases, which are relevant for NPF in boreal forests like $\mathrm{H}_{2} \mathrm{SO}_{4}$, Boy et al. (2005) performed a comprehensive $\mathrm{H}_{2} \mathrm{SO}_{4}$ closure study within the framework of the EU project QUEST. The measurements

\footnotetext{
16 SCIs are involved in several consecutive reactions: Reaction (1): Reaction of SCIs with carbonyl compounds ( $\equiv$ co-products of ozonolysis) to form low-volatility compounds, which nucleate to form secondary ozonides (SOZs) or condense onto nucleated clusters; Reaction (2): Reaction of SCIs with $\mathrm{H}_{2} \mathrm{O}$ to produce high-volatility compounds (evaporation); Reaction (3): Reaction of SCIs with $\mathrm{SO}_{2}$ to form organic sulphates (Bonn and Moortgat, 2003). The SCI-carbonyl compound reaction (1) competes with the SCI- $\mathrm{H}_{2} \mathrm{O}$ reaction (2). Hence, the absence of $\mathrm{H}_{2} \mathrm{O}$ vapour favours reaction (1), and the presence of $\mathrm{H}_{2} \mathrm{O}$ vapour favours reaction (2). This explains the observed anti-correlation between the nucleation intensity and atmospheric $\mathrm{H}_{2} \mathrm{O}$ vapour concentration (Boy and Kulmala, 2002a; Bonn and Moortgat, 2003).
} 
were performed during an intensive measurement campaign in Hyytiälä (17 March to the 13 April 2003). The following results are obtained:

- For the considered period, the authors reported on daytime mean values of $\mathrm{SO}_{2}$ varying in the interval $(0.285$ $4.943) \times 10^{10} \mathrm{~cm}^{-3}$ with an averaged value over the whole period of $1.065 \times 10^{10} \mathrm{~cm}^{-3}$ (Boy et al., 2005, Table 1). From an air mass classification Boy et al. (2005, Table 6) found, that during more polluted days, resulting from anthropogenic influence (traffic, industry, households), the $\mathrm{SO}_{2}$ background concentration was two to six times higher compared to the "clean air mass" case (clean air mass: $0.607 \times 10^{10} \mathrm{~cm}^{-3}$, polluted air mass: $\left.1.74 \times 10^{10} \mathrm{~cm}^{-3}\right)$.

- The observed daytime mean values of $\mathrm{H}_{2} \mathrm{SO}_{4}$ were found to vary in the interval $(0.148-8.553) \times 10^{6} \mathrm{~cm}^{-3}$, with an averaged value over the whole period of $2.942 \times 10^{6} \mathrm{~cm}^{-3}$. The observed maximum midday $\mathrm{H}_{2} \mathrm{SO}_{4}$ concentrations varied in the range $(0.03-1.9) \times 10^{7} \mathrm{~cm}^{-3}$. During more polluted days, resulting from anthropogenic influence, the measured $\mathrm{H}_{2} \mathrm{SO}_{4}$ background concentration was approximately 1.46 times higher compared to the "clean air mass" case (clean air mass: $2.26 \times 10^{6} \mathrm{~cm}^{-3}$, polluted air mass: $\left.3.31 \times 10^{6} \mathrm{~cm}^{-3}\right)$.

- The daily maxima for the $\mathrm{OH}$ concentration were found to be in the range $4.1 \times 10^{5}-1.8 \times 10^{6} \mathrm{~cm}^{-3}$. During more polluted days, the $\mathrm{OH}$ concentration was approximately by a factor of 0.9 times lower compared to the clean air mass (clean air mass: $5.13 \times 10^{5} \mathrm{~cm}^{-3}$, polluted air mass: $4.64 \times 10^{5} \mathrm{~cm}^{-3}$ ) (Boy et al., 2005, Table 6).

- Boy et al. (2005, Table 5) evaluated the contribution of $\mathrm{H}_{2} \mathrm{SO}_{4}$ to the particle diameter growth rates in the nucleation mode between 3 and $25 \mathrm{~nm}$. The growth rate fraction ${ }^{17}$ for $\mathrm{H}_{2} \mathrm{SO}_{4}$ was previously found to range from 4-31\% (Boy et al., 2003, from analysis of two-year time series from Hyytiälä). Boy et al. (2005, Table 5) found an average value of $8.8 \%$ (empirically derived values in the range $3.2-16.9 \%$ ) and concluded: "The results indicate, that the concentration of sulphuric acid seems always to be high enough during particle formation periods to participate in the growth process of the aerosols and can reach on certain days fractions up to $17 \%$ and most probably higher" (Boy et al., 2005, pp. 874-875). Apart from this it was found, that the $\mathrm{H}_{2} \mathrm{SO}_{4}$ contribution (derived from measured $\mathrm{H}_{2} \mathrm{SO}_{4}$ concentration) to the particle growth

\footnotetext{
${ }^{17}$ The growth rate fraction is the percentage of the growth rate, which is explained by $\mathrm{H}_{2} \mathrm{SO}_{4}$ vapour alone. The total growth rate is experimentally determined from measurements using a Differential Mobility Particle Sizer (DMPS).
}

does not depend on the air mass influence (clean air mass: $8.68 \%$, polluted air mass: $8.78 \%$ ) (Boy et al., 2005, Table 6). Concerning this unexpected result the authors concluded: "However, the nearly identical contribution of sulphuric acid to the particle growth during 'polluted' periods compared to the 'clean' days is unexpected. These results indicate, that sulphuric acid always participated during the time of the campaign between 3 to $17 \%$ in the aerosol condensation growth of the nucleation mode particles" (Boy et al., 2005, p. 875).

In their conclusions Boy et al. (2005, p. 877) summarised: "Obviously sulphuric acid is involved (fraction between 3 to 17\%) in new particle production and growth of aerosols over boreal forest regions in Northern Europe, although it might be not the key parameter in the particle formation process itself."

\section{Summary}

Based on a revised columnar high-order model, two nucleation scenarios were simulated and compared with a number of previous observations of NPF bursts in the CBL. The aim was to evaluate the model capability to predict the evolution of the UCN number concentration near the ground and to elucidate the mechanisms contributing to burst formation. From the compilation of previous findings on NPF, the following conclusions can be drawn with respect to the scenario simulations performed in Paper III:

1. The $\mathrm{SO}_{2}$ concentrations observed at the Hyytiälä measurement site and reported in the $\mathrm{H}_{2} \mathrm{SO}_{4}$ closure study performed by Boy et al. (2005), is on average lower than that considered in the scenario of Paper III (see initial profile in Fig. 2a and time-height cross section in Fig. 3b).

2. The upper limit of reported $\mathrm{H}_{2} \mathrm{SO}_{4}$ concentrations in Hyytiälä according to the study of Boy et al. (2005) is two orders of magnitude lower than the simulated maximum of the binary case in Paper III (Fig. 3e) and one order of magnitude lower than the simulated maximum of the ternary case (Fig. 3f).

3. Boy et al. (2005, Table 2, reaction nb. 14) assumed for the rate of $\mathrm{H}_{2} \mathrm{SO}_{4}$ production from the reaction of $\mathrm{SO}_{2}$ with $\mathrm{OH}$, a value of $k_{14}=9.82 \times 10^{-19}$ $\mathrm{m}^{3}$ molecules ${ }^{-1} \mathrm{~s}^{-1}$. In Paper III, a value of $k_{1}=$ $1.5 \times 10^{-18} \mathrm{~m}^{3}$ molecules ${ }^{-1} \mathrm{~s}^{-1}$ was assumed, which leads to a 1.53 times higher $\mathrm{H}_{2} \mathrm{SO}_{4}$ production rate compared to that assumed in the study of Boy et al. (2005).

4. The semi-empirical formula for the $\mathrm{OH}$ prediction used in Paper III (Fig. 3a, Liu et al. (2001)) gives a maximum 
of the $\mathrm{OH}$ concentration, which is one order of magnitude higher than that calculated by Boy et al. (2005).

5. Compared to the values given by Boy et al. (2005), the $\mathrm{H}_{2} \mathrm{SO}_{4}$ concentrations in the present scenario simulations are higher due to (a) the higher $\mathrm{SO}_{2}$ concentration, (b) the higher $\mathrm{OH}$ concentration, (c) the higher production rate of $\mathrm{H}_{2} \mathrm{SO}_{4}$, (d) the lower sticking probability for $\mathrm{H}_{2} \mathrm{SO}_{4}$ vapour and (e) the very low aerosol background concentration assumed in the scenario calculations of Paper III. Therefore, the nucleation rate from the classical nucleation theory is overpredicted.

6. $\mathrm{H}_{2} \mathrm{SO}_{4}$ is neither the only one nor the ultimate condensable vapour to explain the NPF burst behaviour, especially the condensation growth of newly formed particles in forest regions. This is a strong empirical hint at the role of other than inorganic vapours for NPF, such as organic low-volatility compounds resulting from $\mathrm{O}_{3}$ reactions with compounds from biogenic emissions. With respect to the simulations performed in Paper III it seems, that the evaluated binary mechanism leading to NPF does not correspond to the NPF mechanism, hypothesised to occur in boreal forests. Hence, the simulated "inorganic" NPF scenarios can not be assigned to forest regions, where NPF and growth are apparently strongly correlated with biogenic emissions and organic compounds. An accompanying evaluation of $\mathrm{CO}_{2}$ measurements can help to classify, which kind of scenarios must be considered.

7. The impact of $\mathrm{H}_{2} \mathrm{O}$ vapour on the nucleation rate is quite varying, depending on the considered nucleation mechanism. According to the classical binary $\mathrm{H}_{2} \mathrm{O} / \mathrm{H}_{2} \mathrm{SO}_{4}$ nucleation theory, $\mathrm{H}_{2} \mathrm{O}$ vapour favours $\mathrm{NPF}$, according to ternary $\mathrm{H}_{2} \mathrm{O} / \mathrm{H}_{2} \mathrm{SO}_{4} / \mathrm{NH}_{3}$ nucleation theory and according to organic nucleation via chemical reactions involving SCIs, $\mathrm{H}_{2} \mathrm{O}$ vapour disfavours nucleation and according to the parameterisation of the collision-controlled binary nucleation rate proposed by Weber et al. (1996), $\mathrm{H}_{2} \mathrm{O}$ vapour does not explicitly affect the nucleation.

8. The large differences between the binary and ternary case scenario indicate, that $\mathrm{NH}_{3}$ can not only serve as a tuning parameter in nucleation modelling. Its contribution to the evolution of the NPF burst pattern is much more complicated and reflects the influence of CBL turbulence as well as the strong non-linearity of the ternary nucleation rate.

9. The scenario simulations performed in Paper III show, e.g., that completely different mechanism can lead to NPF bursts observable in the surface layer, even if their amplitude, phase and local origin (in situ vs. ex situ production) are quite different. We need more observations, most notably throughout the PBL, to get deeper insight into the controlling parameters and mechanisms leading to NPF.

10. A state-of-the-art hypothesis on the contribution of CBL turbulence to NPF burst evolution could be supported by the model. Furthermore, from a literature review a number of observations regarding the link between turbulence and NPF could be identified, whose burst patterns support the contribution of CBL turbulence to the NPF burst evolution simulated here. Observations, which do not correspond to the considered scenarios were discussed with respect to possible reasons for the differences between model and observation.

11. With respect to the application of box models to simulate NPF bursts, the present study shows, that CBL turbulence, which can not be explicitly considered in such models, can strongly affect the spatio-temporal occurrence of nucleation and the NPF burst evolution.

12. As the present study is a purely conceptual one, a comprehensive model evaluation remains to be performed. It has become clear, that profile measurements of physicochemical parameters throughout the CBL, from both in situ and remote sensing techniques, are needed to constrain the degrees of freedom of a model like the present one, e.g., for the model setup. Apart from that, enhanced scenario simulations are necessary to verify and/or falsify, respectively, the other NPF hypotheses of Nilsson et al. (2001a, Section 4.1, item (2)-(4)). Boy et al. (2005) demonstrated, that the experimentally derived growth rate is a robust and very effective parameter to valuate the role of compounds, hypothesised to be involved in both nucleation and growth. Therefore, it is a good diagnostic parameter for model evaluation.

13. Altogether, the present model was demonstrated to be an useful tool to simulate gas-aerosol-turbulence interactions in the PBL, especially to elucidate the role of CBL turbulence in the evolution of NPF bursts. Moreover, the model delivers the necessary prognostic highorder moments, that are required to explicitly parameterise the influence of subgridscale turbulence on the mean nucleation rate, such as proposed by Easter and Peters (1994), Nilsson and Kulmala (1998) and Hellmuth and Helmert (2002).

\section{Conclusions}

We fully agree with Hyvönen et al. (2005, p. 3354) in their conclusion: "Although we found a connection between the occurrence of nucleation and two key variables, the detailed chemistry still remains speculative. One missing link in our study is the concentration of biogenic Volatile Organic Compounds (VOC) emissions, which are expected to be of high 
importance even at the low concentrations. [...] One possible cause of confusion is the possibility of two or even more different nucleation mechanism acting simultaneously in the atmosphere. One such combination is clear-air nucleation vs. pollution nucleation, another possibility is combination of neutral and ion-induced nucleation."

Following Hegel's notion of conclusion one might add:

Thesis $^{18}$ :

"The strongest arguments prove nothing so long as the conclusions are not verified by experience. Experimental science is the queen of sciences and the goal of all speculation.” (ROGER BACON)

\section{Antithesis ${ }^{19}$ :}

"It is most important to have a beautiful theory. And if the observations don't support it, don't be too distressed, but wait a bit and see if some error in the observations doesn't show up." (PAUL DIRAC)

\section{Synthesis ${ }^{20}$ :}

With respect to atmospheric nucleation there are two alternatives:

(a) Either we have both "queenly scientific experiments" and a "beautiful theory" or

(b) we have practically nothing to be applied in multiscale atmospheric models.

Acknowledgements. The work was realised at the IfT Modelling Department headed by E. Renner within the framework of IfT main research direction 1 "Evolution, transport and spatio-temporal distribution of the tropospheric aerosol". For the motivation and numerous discussions on the subject of the present Paper I am very indebted to D. Mironov, E. Renner, K. Bernhardt, E. Schaller, M. Kulmala, A. A. Lushnikov, M. Boy, R. Wolke, F. Stratmann, H. Siebert, T. Berndt and J. W. P. Schmelzer. Sincerest thanks are given to M. Kulmala and M. Boy for the opportunity to present and discuss previous results at the Department of Physics at the University of Helsinki as well as to J. W. P. Schmelzer for the chance to discuss selected aspects of cluster formation under atmospheric conditions, generalisation of classical Gibbs theory and phase transformations in multicomponent systems during the $X^{\text {th }}$ Research Workshop on Nucleation Theory and Applications at the Bogoliubov Laboratory of Theoretical Physics of the Joint Institute for Nuclear Research (JINR), Dubna. In this context, I want to express special thanks also to A. K. Shchekin, A. S. Abyzov, H. Heinrich and I. S. Gutzow. Many thanks go to the editor and to the three reviewers for their helpful comments, additional

\footnotetext{
${ }^{18}$ Taken from Schmelzer et al. (2005).

${ }^{19}$ Taken from Schmelzer and Schmelzer Jr. (2002).

${ }^{20} \mathrm{We}$ feel free to cite an ostensive comment of I. Gutzow, who noticed in view of the high numbers of parameters, determining the spatio-temporal evolution of atmospheric NPF: "The identification and elucidation of the key processes leading to atmospheric nucleation is as exiting as the search for the murder in a crime story."
}

references and suggestions to improve the manuscript. Special thanks go also to N. Otto and N. Deisel for their strong support during the technical processing as well as to V. Grützun and $\mathrm{M}$. Reichelt for the proofreading of the manuscript.

Edited by: M. Kulmala

\section{References}

Aalto, P., Hämeri, K., Becker, E., Weber, R., Salm, J., Mäkelä, J. M., Hoell, C., O’Dowd, C. D., Karlsson, H., Hansson, H.C., Väkevä, M., Koponen, I. K., Buzorius, G., and Kulmala, M.: Physical characterization of aerosol particles during nucleation events, Tellus, 53B, 344-358, 2001.

Allan, J. D., Alfarra, M. R., Bower, K. N., Coe, H., Jayne, J. T., Worsnop, D. R., Aalto, P. P., Kulmala, M., Hyötyläinen, T., Cavalli, F., and Laaksonen, A.: Size and composition measurements of background aerosol and new particle growth in a Finnish forest during QUEST 2 using an aerodyne aerosol mass spectrometer, Atmos. Chem. Phys., 6, 315-327, 2006, http://www.atmos-chem-phys.net/6/315/2006/.

Andersson-Sköld, Y. and Simpson, D.: Secondary organic aerosol formation in northern Europe: A model study, J. Geophys. Res., 106(D7), 7357-7374, 2001.

Andreani-Aksoyoglu, S., Prévôt, A. S. H., Baltensperger, U., Keller, J., and Dommen, J.: Modeling of formation and distribution of secondary aerosols in the Milan area (Italy), J. Geophys. Res., 109, D05306, doi:10.1029/2003JD004231, 2004.

Berndt, T., Böge, O., and Stratmann, F.: Gas-phase ozonolysis of $\alpha$-pinene: Gaseous products and particle formation, Atmos. Environ., 37, 3933-3945, 2003.

Birmili, W. and Wiedensohler, A.: New particle formation in the continental boundary layer: Meteorological and gas phase parameter influence, Geophys. Res. Lett., 27(20), 3325-3328, 2000.

Birmili, W., Wiedensohler, A., Plass-Dülmer, C., and Berresheim, H.: Evolution of newly formed aerosol particles in the continental boundary layer: A case study including $\mathrm{OH}$ and $\mathrm{H}_{2} \mathrm{SO}_{4}$ measurements, Geophys. Res. Lett., 27(15), 2205-2208, 2000.

Birmili, W., Berresheim, H., Plass-Dülmer, C., Elste, T., Gilge, S., Wiedensohler, A., and Uhrner, U.: The Hohenpeissenberg aerosol formation experiment (HAFEX): A long-term study including size-resolved aerosol, $\mathrm{H}_{2} \mathrm{SO}_{4}, \mathrm{OH}$, and monoterpenes measurements, Atmos. Chem. Phys., 3, 361-376, 2003, http://www.atmos-chem-phys.net/3/361/2003/.

Bonn, B. and Moortgat, G. K.: Sesquiterpene ozonolysis: Origin of atmospheric new particle formation from biogenic hydrocarbons, Geophys. Res. Lett., 30(11), 1585, doi:10.1029/2003GL017000, 2003.

Bonn, B., v. Kuhlmann, R., and Lawrence, M. G.: High contribution of biogenic hydroperoxides to secondary organic aerosol formation, Geophys. Res. Lett., 31, L10108, doi:10.1029/2003GL019172, 2004.

Boy, M. and Kulmala, M.: Nucleation events in the continental boundary layer: Influence of physical and meteorological parameters, Atmos. Chem. Phys., 2, 1-16, 2002a.

Boy, M. and Kulmala, M.: The part of the solar spectrum with the highest influence on the formation of SOA in the continental boundary layer, Atmos. Chem. Phys., 2, 375-386, 2002 b. 
Boy, M., Rannik, Ü., Lehtinen, K. E. J., Tarvainen, V., Hakola, H., and Kulmala, M.: Nucleation events in the continental boundary layer: Long-term statistical analyses of aerosol relevant characteristics, J. Geophys. Res., 108(D21), 4667, doi:10.1029/2003JD003838, 2003.

Boy, M., Petäjä, T., Dal Maso, M., Rannik, Ü., Rinne, J., Aalto, P., Laaksonen, A., Vaattovaara, P., Joutsensaari, J., Hoffmann, T., Warnke, J., Apostolaki, M., Stephanou, E. G., Tsapakis, M., Kouvarakis, A., Pio, C., Carvalho, A., Römpp, A., Moortgat, G., Spirig, C., Guenther, A., Greenberg, J., Ciccioli, P., and Kulmala, M.: Overview of the field measurement campaign in Hyytiälä, August 2001 in the framework of the EU project OSOA, Atmos. Chem. Phys., 4, 657-678, 2004, http://www.atmos-chem-phys.net/4/657/2004/.

Boy, M., Kulmala, M., Ruuskanen, T. M., Pihlatie, M., Reissell, A., Aalto, P. P., Keronen, P., Dal Maso, M., Hellen, H., Hakola, H., Jansson, R., Hanke, M., and Arnold, F.: Sulphuric acid closure and contribution to nucleation mode particle growth, Atmos. Chem. Phys., 5, 863-878, 2005,

http://www.atmos-chem-phys.net/5/863/2005/.

Buzorius, G., Rannik, Ü., Nilsson, D., and Kulmala, M.: Vertical fluxes and micrometeorology during aerosol particle formation events, Tellus, 53B, 394-405, 2001.

Buzorius, G., Rannik, Ü., Aalto, P., dal Maso, M., Nilsson, E. D., Lehtinen, K. E. J., and Kulmala, M.: On particle formation prediction in continental boreal forest using micrometeorological parameters, J. Geophys. Res., 108(D13), 4377, doi:10.1029/2002JD002850, 2003.

Cavalli, F., Facchini, M. C., Decesari, S., Emblico, L., Mircea, M., Jensen, N. R., and Fuzzi, S.: Size-segregated aerosol chemical composition at a boreal site in southern Finland, during the QUEST project, Atmos. Chem. Phys., 6, 993-1002, 2006, http://www.atmos-chem-phys.net/6/993/2006/.

Chung, S. H. and Seinfeld, J. H.: Global distribution and climate forcing of carbonaceous aerosols, J. Geophys. Res., 107(D19), 4407, doi:10.1029/2001JD001397, 2002.

Clement, C. F., Pirjola, L., dal Maso, M., Mäkelä, J. M., and Kulmala, M.: Analysis of particle formation bursts observed in Finland, J. Aerosol Sci., 32, 217-236, 2001.

Dal Maso, M., Kulmala, M., Lehtinen, K. E. J., Mäkelä, J. M., Aalto, P., and O'Dowd, C. D.: Condensation and coagulation sinks and formation of nucleation mode particles in coastal and boreal forest boundary layers, J. Geophys. Res., 107(D19), 8097, doi:10.1029/2001JD001053, 2002.

Dal Maso, M., Kulmala, M., Riipinen, I., Wagner, R., Hussein, T., Aalto, P. P., and Lehtinen, K. E. J.: Formation and growth of fresh atmospheric aerosols: Eight years of aerosol size distribution data from SMEAR II, Hyytiälä, Finland, Boreal Environ. Res., 10, 323-336, 2005.

Easter, R. C. and Peters, L. K.: Binary homogeneous nucleation: Temperature and relative humidity fluctuations, nonlinearity, and aspects of new particle production in the atmosphere, J. Appl. Meteorol., 33, 775-784, 1994.

Fuzzi, S., Andreae, M. O., Huebert, B. J., Kulmala, M., Bond, T. C., Boy, M., Doherty, S. J., Guenther, A., Kanakidou, M., Kawamura, K., Kerminen, V.-M., Lohmann, U., Russell, L. M., and Pöschl, U.: Critical assessment of current state of scientific knowledge, terminology, and research needs concerning the role of organic aerosols in the atmosphere, climate, and global change, Atmos. Chem. Phys., 6, 2017-2038, 2006, http://www.atmos-chem-phys.net/6/2017/2006/.

Gaydos, T. M., Stanier, C. O., and Pandis, S. N.: Modeling of in situ ultrafine atmospheric particle formation in the eastern United States, J. Geophys. Res., 110, D07S12, doi:10.1029/2004JD004683, 2005.

Guenther, A., Hewitt, C. N., Erickson, D., Fall, R., Geron, C., Graedel, T., Harley, P., Klinger, L., Lerdau, M., McKay, W. A., Pierce, T., Scholes, B., Steinbrecher, R., Tallamraju, R., Taylor, J., and Zimmerman, P.: A global model of natural volatile organic compound emissions, J. Geophys. Res., 100(D5), 88738892, 1995.

Held, A., Nowak, A., Birmili, W., Wiedensohler, A., Forkel, R., and Klemm, O.: Observations of particle formation and growth in a mountainous forest region in central Europe, J. Geophys. Res., 109, D23204, doi:10.1029/2004JD005346, 2004.

Hellén, H., Hakola, H., Reissell, A., and Ruuskanen, T. M.: Carbonyl compounds in boreal coniferous forest air in Hyytiälä, Southern Finland, Atmos. Chem. Phys., 4, 1771-1780, 2004, http://www.atmos-chem-phys.net/4/1771/2004/.

Hellmuth, O. and Helmert, J.: Parameterization of turbulenceenhanced nucleation in large scale models: Conceptual study, in: Air Pollution Modeling and Its Application XV, edited by Borrego, C. and Schayes, G., pp. 295-304, Kluwer Academic/ Plenum Publishers, New York, 2002.

Hoffmann, T., Odum, J. R., Bowman, F., Collins, D., Klockow, D., Flagan, R. C., and Seinfeld, J. H.: Formation of organic aerosols from the oxidation of biogenic hydrocarbons, J. Atmos. Chem., 26, 189-222, 1997.

Hyvönen, S., Junninen, H., Laakso, L., Dal Maso, M., Grönholm, T., Bonn, B., Keronen, P., Aalto, P., Hiltunen, V., Pohja, T., Launiainen, S., Hari, P., Mannila, H., and Kulmala, M.: A look at aerosol formation using data mining techniques, Atmos. Chem. Phys., 5, 3345-3356, 2005,

http://www.atmos-chem-phys.net/5/3345/2005/.

Iinuma, Y., Böge, O., Gnauk, T., and Herrmann, H.: Aerosolchamber study of the $\alpha$-pinene $/ \mathrm{O}_{3}$ reaction: Influence of particle acidity on aerosol yields and products, Atmos. Environ., 38, 761-773, 2004.

Kamens, R. M. and Jaoui, M.: Modeling aerosol formation from $\alpha$-pinene $+\mathrm{NO}_{\mathrm{x}}$ in the presence of natural sunlight using gasphase kinetics and gas-particle partioning theory, Environ. Sci. Tech., 35, 1394-1405, 2001.

Kavouras, I. G., Mihalopoulos, N., and Stephanou, E. G.: Formation of atmospheric particles from organic acids produced by forests, Nature, 395, 683-686, 1998.

Kawamura, K., Umemoto, N., Mochida, M., Bertram, T., Howell, S., and Huebert, B. J.: Water-soluble dicarboxylic acids in the tropospheric aerosols collected over east Asia and western North Pacific by ACE-Asia C-130 aircraft, J. Geophys. Res., 108(D23), 8639, doi:10.1029/2002JD003256, 2003.

Kerminen, V.-M. and Kulmala, M.: Analytical formulae connecting the "real" and the "apparent" nucleation rate and the nuclei number concentration for atmospheric nucleation events, J. Aerosol Sci., 33, 609-622, 2002.

Komppula, M., Dal Maso, M., Lihavainen, H., Aalto, P. P., Kulmala, M., and Viisanen, Y.: Comparison of new particle formation events at two locations in northern Finland, Boreal Environ. Res., 8, 395-404, 2003a. 
Komppula, M., Lihavainen, H., Hatakka, J., Paatero, J., Aalto, P., Kulmala, M., and Viisanen, Y.: Observations of new particle formation and size distributions at two different heights and surroundings in subarctic area in northern Finland, J. Geophys. Res., 108(D9), 4295, doi:10.1029/2002JD002939, 2003b.

Korhonen, P., Kulmala, M., Laaksonen, A., Viisanen, Y., McGraw, R., and Seinfeld, J. H.: Ternary nucleation of $\mathrm{H}_{2} \mathrm{SO}_{4}, \mathrm{NH}_{3}$, and $\mathrm{H}_{2} \mathrm{O}$ in the atmosphere, J. Geophys. Res., 104(D21), 26349 26353, 1999.

Krejci, R., Ström, J., de Reus, M., Hoor, P., Williams, J., Fischer, H., and Hansson, H.-C.: Evolution of aerosol properties over the rain forest in Surinam, South America, observed from aircraft during the LBA-CLAIRE 98 experiment, J. Geophys. Res., 108(D18), 4561, doi:10.1029/2001JD001375, 2003.

Kulmala, M.: How particles nucleate and grow, Science, 302, 10001001, 2003.

Kulmala, M., Laaksonen, A., and Pirjola, L.: Parameterizations for sulfuric acid/ water nucleation rates, J. Geophys. Res., 103(D7), 8301-8307, 1998a.

Kulmala, M., Toivonen, A., Mäkelä, J. M., and Laaksonen, A.: Analysis of the growth of nucleation mode particles observed in boreal forest, Tellus, 50B, 449-462, 1998b.

Kulmala, M., Pirjola, L., and Mäkelä, J. M.: Stable sulphate clusters as a source a new atmospheric particles, Nature, 404, 66-69, 2000.

Kulmala, M., Dal Maso, M., Mäkelä, J. M., Pirjola, L., Väkevä, M., Aalto, P., Miikkulainen, P., Hämeri, K., and O'Dowd, C. D.: On the formation, growth and composition of nucleation mode particles, Tellus, 53B, 479-490, 2001a.

Kulmala, M., Hämeri, K., Aalto, P. P., Mäkelä, J. M., Pirjola, L., Nilsson, E. D., Buzorius, G., Rannik, Ü., Dal Maso, M., Seidl, W., Hoffman, T., Janson, R., Hansson, H.-C., Viisanen, Y., Laaksonen, A., and O'Dowd, C. D.: Overview of the international project on biogenic aerosol formation in the boreal forest (BIOFOR), Tellus, 53B, 324-343, 2001b.

Kulmala, M., Korhonen, P., Napari, I., Karlsson, A., Berresheim, H., and O'Dowd, C. D.: Aerosol formation during PARFORCE: Ternary nucleation of $\mathrm{H}_{2} \mathrm{SO}_{4}, \mathrm{NH}_{3}$, and $\mathrm{H}_{2} \mathrm{O}$, J. Geophys. Res., 107(D19), 8111, doi:10.1029/2001JD000900, 2002.

Kulmala, M., Kerminen, V.-M., Anttila, T., Laaksonen, A., and O'Dowd, C. D.: Organic aerosol formation via sulphate cluster activation, J. Geophys. Res., 109, D04205, doi:10.1029/2003JD003961, 2004a.

Kulmala, M., Laakso, L., Lehtinen, K. E. J., Riipinen, I., Dal Maso, M., Anttila, T., Kerminen, V.-M., Hõrrak, U., Vana, M., and Tammet, H.: Initial steps of aerosol growth, Atmos. Chem. Phys., 4, 2553-2560, 2004b.

Kulmala, M., Suni, T., Lehtinen, K. E. J., Dal Maso, M., Boy, M., Reissell, A., Rannik, Ü., Aalto, P., Keronen, P., Hakola, H., Bäck, J., Hoffmann, T., Vesala, T., and Hari, P.: A new feedback mechanism linking forests, aerosols, and climate, Atmos. Chem. Phys., 4, 557-562, 2004c.

Kulmala, M., Vehkamäki, H., Petäjä, T., Dal Maso, M., Lauri, A., Kerminen, V.-M., Birmili, W., and McMurry, P. H.: Formation and growth rates of ultrafine atmospheric particles: A review of observations, J. Aerosol Sci., 35, 143-176, 2004d.

Kulmala, M., Lehtinen, K. E. J., Laakso, L., Mordas, G., and Hämeri, K.: On the existence of neutral atmospheric clusters, Boreal Environ. Res., 10, 79-87, 2005a.
Kulmala, M., Petäjä, T., Mönkkönen, P., Koponen, I. K., Dal Maso, M., Aalto, P. P., Lehtinen, K. E. J., and Kerminen, V.-M.: On the growth of nucleation mode particles: Source rates of condensable vapor in polluted and clean environments, Atmos. Chem. Phys., 5, 409-416, 2005b.

Kulmala, M., Lehtinen, K. E. J., and Laaksonen, A.: Cluster activation theory as an explanation of the linear dependence between formation rate of $3 \mathrm{~nm}$ particles and sulphuric acid concentration, Atmos. Chem. Phys., 6, 787-793, 2006, http://www.atmos-chem-phys.net/6/787/2006/.

Laakso, L., Anttila, T., Lehtinen, K. E. J., Aalto, P. P., Kulmala, M., Hõrrak, U., Paatero, J., Hanke, M., and Arnold, F.: Kinetic nucleation and ions in boreal forest particle formation events, Atmos. Chem. Phys., 4, 2353-2366, 2004a.

Laakso, L., Petäjä, T., Lehtinen, K. E. J., Kulmala, M., Paatero, J., Hõrrak, U., Tammet, H., and Joutsensaari, J.: Ion production rate in a boreal forest based on ion, particle and radiation measurements, Atmos. Chem. Phys., 4, 1933-1943, 2004b.

Lee, S., Jang, M., and Kamens, R. M.: SOA formation from the photooxidation of $\alpha$-pinene in the presence of freshly emitted diesel soot exhaust, Atmos. Environ., 38, 2597-2605, 2004.

Liu, X., Hegg, D. A., and Stoelinga, M. T.: Numerical simulation of new particle formation over the northwest Atlantic using the MM5 mesoscale model coupled with sulfur chemistry, J. Geophys. Res., 106(D9), 9697-9715, 2001.

Mäkelä, J. M., Aalto, P., Jokinen, V., Pohja, T., Nissinen, A., Palmroth, S., Markkanen, T., Seitsonen, K., Lihavainen, H., and Kulmala, M.: Observations of ultrafine aerosol particle formation and growth in boreal forest, Geophys. Res. Lett., 24(10), 1219 1222, 1997.

Marti, J. J., Weber, R. J., McMurry, P. H., Eisele, F., Tanner, D., and Jefferson, A.: New particle formation at a remote continental site: Assessing the contributions of $\mathrm{SO}_{2}$ and organic precursors, J. Geophys. Res., 102(D5), 6331-6339, 1997.

Napari, I., Noppel, M., Vehkamäki, H., and Kulmala, M.: An improved model for ternary nucleation of sulfuric acid-ammoniawater, J. Chem. Phys., 116, 4221-4227, 2002a.

Napari, I., Noppel, M., Vehkamäki, H., and Kulmala, M.: Parametrization of ternary nucleation rates for $\mathrm{H}_{2} \mathrm{SO}_{4}$ $\mathrm{NH}_{3}-\mathrm{H}_{2} \mathrm{O}$ vapors, J. Geophys. Res., 107(D19), 4381, doi:10.1029/2002JD002132, 2002b.

Narukawa, M., Kawamura, K., Okada, K., Zaizen, Y., and Makino, Y.: Aircraft measurement of dicarboxylic acids in the free tropospheric aerosols over the western to central North Pacific, Tellus, 55B, 777-786, 2003.

Nilsson, E. D. and Kulmala, M.: The potential for atmospheric mixing processes to enhance the binary nucleation rate, J. Geophys. Res., 103(D1), 1381-1389, 1998.

Nilsson, E. D., Paatero, J., and Boy, M.: Effects of air masses and synoptic weather on aerosol formation in the continental boundary layer, Tellus, 53B, 462-478, 2001a.

Nilsson, E. D., Rannik, Ü., Kulmala, M., Buzorius, G., and O'Dowd, C. D.: Effects of continental boundary layer evolution, convection, turbulence and entrainment, on aerosol formation, Tellus, 53B, 441-461, 2001b.

Saathoff, H.: Die Bildung sekundären organischen Aerosols durch Oxidation von $\alpha$-Pinenen, in: Jahresbericht 2003, pp. 1-2, Helmholtz-Gemeinschaft, Forschungszentrum Karlsruhe, IMK-AAF Institut für Meteorologie und Kli- 
maforschung, Atmosphärische Aerosolforschung, AIDA, http://imk-aida.fzk.de/projects/reports/AAF2003.pdf, 2003.

Schmelzer, J. W. P. and Schmelzer Jr., J.: Kinetics of bubble formation and the tensile strength of liquids, in: Nucleation Theory and Applications, edited by Schmelzer, J. W. P., Röpke, G., and Priezzhev, V. B., pp. 88-119, JINR Joint Institute for Nuclear Research, Bogoliubov Laboratory of Theoretical Physics, Dubna, 2002.

Schmelzer, J. W. P., Boltachev, G. S., and Baidakov, V. G.: Is Gibbs' thermodynamic theory of heterogeneous systems really perfect?, in: Nucleation Theory and Applications, edited by Schmelzer, J. W. P., pp. 418-446, Wiley-VCH Verlag GmbH \& Co. KGaA, Weinheim, 2005.

Sellegri, K., Hanke, M., Umann, B., Arnold, F., and Kulmala, M.: Measurements of organic gases during aerosol formation events in the boreal forest atmosphere during QUEST, Atmos. Chem. Phys., 5, 373-384, 2005a.

Sellegri, K., Umann, B., Hanke, M., and Arnold, F.: Deployment of a ground-based CIMS apparatus for the detection of organic gases in the boreal forest during the QUEST campaign, Atmos. Chem. Phys., 5, 357-372, 2005b.

Siebert, H., Stratmann, F., and Wehner, B.: First observations of increased ultrafine particle number concentrations near the inversion of a continental planetary boundary layer and its relation to ground-based measurements, Geophys. Res. Lett., 31, L09102, doi:10.1029/2003GL019086, 2004.

Steinbrecher, R. and the BEWA2000-Team: Regional biogenic emissions of reactive volatile organic compounds (BVOC) from forests: Process studies, modelling and validation experiments (BEWA2000), AFO2000-Newsletter, 8(9-2004), 7-10, unpublished manuscript, 2004.
Strader, R., Lurmann, F., and Pandis, S. N.: Evaluation of secondary organic aerosol formation in winter, Atmos. Environ., 33, 48494863, 1999.

Stratmann, F., Siebert, H., Spindler, G., Wehner, B., Althausen, D., Heintzenberg, J., Hellmuth, O., Rinke, R., Schmieder, U., Seidel, C., Tuch, T., Uhrner, U., Wiedensohler, A., Wandinger, U., Wendisch, M., Schell, D., and Stohl, A.: New-particle formation events in a continental boundary layer: First results from the SATURN experiment, Atmos. Chem. Phys., 3, 1445-1459, 2003, http://www.atmos-chem-phys.net/3/1445/2003/.

Uhrner, U., Birmili, W., Stratmann, F., Wilck, M., Ackermann, I. J., and Berresheim, H.: Particle formation at a continental background site: Comparison of model results with observations, Atmos. Chem. Phys., 3, 347-359, 2003, http://www.atmos-chem-phys.net/3/347/2003/.

Weber, R. J., Marti, J. J., McMurry, P. H., Eisele, F. L., Tanner, D. J., and Jefferson, A.: Measured atmospheric new particle formation rates: Implications for nucleation mechanisms, Chem. Eng. Comm., 151, 53-64, 1996.

Ziemann, P. J.: Evidence for low-volatility diacyl peroxides as a nucleating agent and major component of aerosol formed from reactions of $\mathrm{O}_{3}$ and cyclohexene and homologous compounds, $\mathrm{J}$. Phys. Chem. A, 106, 4390-4402, 2002. 